This manuscript is a preprint and has been submitted for publication in Journal of Climate. Please note that, despite having undergone peer-review, the manuscript has yet to be formally accepted for publication. Subsequent versions of this manuscript may have slightly different content. If accepted, the final version of this manuscript will be available via the 'Peer-reviewed Publication DOI' link on the right-hand side of this webpage. Please feel free to contact any of the authors; we welcome feedback. 


\title{
Causes of the Arctic's Lower-Tropospheric Warming Structure
}

\author{
Zachary S. Kaufman* and Nicole Feldl \\ University of California, Santa Cruz, Santa Cruz, California
}

\begin{abstract}
Arctic amplification has been attributed predominantly to a positive lapse rate feedback in winter, when boundary-layer temperature inversions focus warming near the surface. Predicting high-latitude climate change effectively thus requires identifying the local and remote physical processes that set the Arctic's vertical warming structure. In this study, we analyze output from the CESM Large Ensemble's 21st century climate change projection to diagnose the relative influence of two Arctic heating sources, local sea-ice loss and remote changes in atmospheric heat transport. Causal effects are quantified with a statistical inference method, allowing us to assess the energetic pathways mediating the Arctic temperature response and the role of internal variability across the ensemble. We find that a step-increase in latent heat flux convergence causes Arctic lower-tropospheric warming in all seasons, while additionally reducing net longwave cooling at the surface. However, these effects only lead to small and short-lived changes in boundary layer inversion strength. By contrast, a step-decrease in sea-ice extent in the melt season causes, in fall and winter, surface-amplified warming and weakened boundary-layer temperature inversions. Sea-ice loss also enhances surface turbulent heat fluxes and cloud-driven condensational heating, which mediate the atmospheric temperature response. While the aggregate effect of many moist transport events and seasons of sea-ice loss will be different than the response to hypothetical perturbations, our results nonetheless highlight the mechanisms that alter the Arctic temperature inversion in response to $\mathrm{CO}_{2}$ forcing. As sea ice declines, the atmosphere's boundary-layer temperature structure is weakened, static stability decreases, and a thermodynamic coupling emerges between the Arctic surface and the overlying troposphere.
\end{abstract}

\section{Introduction}

Global climate change is characterized by an Arcticamplified pattern of surface warming. This warming pattern is a robust feature of climate models subjected to increases in $\mathrm{CO}_{2}$ (Manabe and Stouffer 1980; Holland and Bitz 2003), and observed Arctic temperatures have warmed at twice the global average in recent decades (Serreze et al. 2009; England et al. 2021). However, considerable uncertainty remains regarding the underlying mechanisms of the Arctic Amplification phenomenon (Smith et al. 2019). Accurate predictions of future warming trends require understanding of the various feedback mechanisms acting at high latitudes. The surface albedo feedback associated with sea-ice loss has long been understood to shape polar climate sensitivity: melting snow and sea ice increases the surface absorption of solar radiation, leading to additional warming (Manabe and Wetherald 1975). However, the changes in sea ice are largest in summer, while Arctic near-surface warming trends are largest in winter ( $\mathrm{Lu}$ and Cai 2009), when shortwave radiative fluxes are small. This discrepancy highlights an additional positive feedback, the high-latitude lapse rate feedback, which is associated with the Arctic's surface-amplified warming in the cold season (Winton 2006). More generally, the lapse rate feedback describes the effect of vertically nonuniform tropospheric warming on the efficiency of radiative cooling to space.

\footnotetext{
*Corresponding author: Zachary S. Kaufman, zskaufma@ucsc.edu
}

The surface-amplified warming characteristic of a positive lapse rate feedback arises in the Arctic due to stable stratification of the wintertime boundary layer, which inhibits upward mixing of thermal anomalies away from the surface (Bintanja et al. 2011). Compared to vertically uniform warming, this bottom-heavy structure necessitates larger surface temperature increases to drive the change in outgoing longwave radiation that balances anthropogenic $\mathrm{CO}_{2}$ forcing (i.e., a positive lapse rate feedback). This situation can be contrasted with the tropics, where deep convection leads $\mathrm{CO}_{2}$-forced warming to maximize in the upper troposphere, producing more efficient radiative cooling and a negative lapse rate feedback. Therefore, the spatial pattern of lapse rate changes drives Arctic amplification in fully coupled climate models (Pithan and Mauritsen 2014; Stuecker et al. 2018), as well as hemispheric asymmetries in projected polar warming, where the Arctic exhibits greater warming than the Antarctic (Hahn et al. 2020).

Though the physical basis for the positive high-latitude lapse rate feedback is well established, its coupled interactions with other aspects of the climate system remain unclear. From a local perspective, quantifying the warming contribution of the Arctic lapse rate feedback is challenging because of its interdependent relationship with sea ice. Reductions in ice cover during the warm season can lead to a buildup of heat in the newly exposed ocean, delaying freeze-up in fall and winter (Serreze et al. 2007b, 2009; Boeke and Taylor 2018). This stored heat can then be 
released to the overlying near-surface atmosphere via enhanced upward turbulent heat fluxes (Manabe and Stouffer 1980; Bintanja and Van der Linden 2013; Dai et al. 2019; Feldl et al. 2020). Supporting this coupled mechanism, modeling experiments that disable or suppress the ice-albedo feedback have shown a corresponding reduction in the polar lapse rate feedback (Graversen et al. 2014; Feldl et al. 2017b).

In addition to local feedbacks, remote processes may also influence Arctic warming through the poleward transport of heat and moisture. Though 21 st century climate change simulations project only small increases in net atmospheric heat transport into the Arctic, compensating decreases in dry static energy transport (Hwang et al. 2011) and increases in latent heat transport (Held and Soden 2006) can be much larger. Beyond the effect of latent heating upon condensation, remotely sourced moisture can contribute to Arctic warming through the water vapor and cloud feedbacks, which increase the infrared opacity of the atmosphere and tend to strengthen downward longwave radiative fluxes (Lee et al. 2017; Yoshimori et al. 2017; Graversen and Langen 2019). These impacts of latent heat transport on the surface radiation budget have been implicated in Arctic warming and sea ice trends (Park et al. 2015a,b; Gong et al. 2017). Further, a tropical mechanism causing Arctic warming has been identified in models forced by prescribed tropical sea surface temperatures (SSTs, Ding et al. 2014; Dong et al. 2019). The tropically excited Arctic warming mechanism has been used to explain observed wintertime near-surface Arctic warming, where anomalous deep convection over the West Pacific promotes Rossby wave propagation towards higher latitudes during the La Niña phase of the El Niño Southern Oscillation (Lee 2012; Liu and Barnes 2015; Baggett and Lee 2017). Finally, remotely sourced Arctic warming can be accomplished by anomalous ocean heat transport, which has been shown to drive multi-year sea-ice declines in many climate models, particularly along continental shelves (Auclair and Tremblay 2018). However, meridional energy flux convergence into the Arctic is dominated by the atmospheric component (Serreze et al. 2007a), which is the primary focus of our study.

The complex interplay between local feedbacks and remote heat transport hampers efforts to isolate an individual process' contribution to Arctic warming. Overcoming this difficulty requires identifying the changes in the Arctic troposphere that are ultimately local or remote in origin. As demonstrated by Feldl et al. (2020), a partitioning of the lapse rate feedback into upper and lower contributions reveals that lower-tropospheric warming is strongly tied to climatological sea-ice extent and sea-ice loss, enhancing the positive lapse rate feedback, while remotely driven increases in heat transport warm the mid-troposphere, weakening the lapse rate feedback in subpolar latitudes. Similar interactions between the lapse rate feedback and atmospheric heat transport have been previously noted by Feldl et al. (2017a); Stuecker et al. (2018). Crucially, this remote influence on the high-latitude lapse rate feedback does not preclude a warming influence on the Arctic surface due to the aforementioned moist transport effects. Direct attributions of polar atmospheric temperature change in a singlecolumn model emphasize the role of $\mathrm{CO}_{2}$ and water vapor in warming the surface and atmospheric heat transport in warming the mid- and upper troposphere, with compensating behavior by the dry heat transport in the presence of a surface heat source (Henry et al. 2021). Lastly, it is well established that enhanced atmospheric heat transport is able to produce Arctic amplification in simulations that have meridionally uniform radiative feedbacks (Merlis and Henry 2018; Armour et al. 2019), suppress the ice-albedo feedback (Graversen and Wang 2009), or lack sea ice altogether (Alexeev et al. 2005), though there is some evidence that this response may be due in part to the idealized nature of the simulations (Kim et al. 2018). Attributions of polar amplification are thus represented differently across models of varying complexity and for different attribution methods.

A pressing challenge in climate science is to understand how sea ice and atmospheric circulation interactively set the Arctic's vertical warming structure during the 21 st century. Using a statistical causal inference approach, we evaluate coupled relationships and causal pathways between time series of sea-ice concentration, Arctic atmospheric temperatures, surface energy fluxes, and meridional heat flux convergence from output of the Community Earth System Model. Though $\mathrm{CO}_{2}$ forcing is the ultimate driver of Arctic warming, we seek to identify and quantify the proximate causes and mediating pathways between sea-ice and heat-transport perturbations and the eventual warming response in a comprehensive model. Such pathways are uncovered using causal network learning algorithms that analyze large numbers of interdependent time series variables at once (Pearl et al. 2000; Spirtes et al. 2000). These novel statistical techniques are just beginning to be applied to the study of Arctic climate (Kretschmer et al. 2016) and their adaptation for geoscience applications is a new and active area of research (Runge et al. 2019). By evaluating the Arctic's temperature inversion in a fully coupled setting, we account for two-way relationships amongst the physical processes of interest. This is a crucial feature of our analysis, as sea ice and atmospheric circulation do not control Arctic climate independently; sea-ice loss, for instance, can itself drive circulation changes in both the atmosphere (Screen et al. 2018; McGraw et al. 2020) and the ocean (Tomas et al. 2016). Our statistical approach therefore disentangles the atmosphere-ocean-ice interactions underlying the high-latitude lapse rate feedback and Arctic amplification. 


\section{Methods}

\section{a. Climate Model Output and Diagnostics}

This study is conducted with output from the Community Earth System Model Large Ensemble (CESM-LE, Kay et al. 2015). The CESM-LE climate change simulation is initialized from an equilibrium preindustrial control state, then subjected to historical greenhouse-gas forcing from 1920 to 2005 and projected forcing from 2005-2100 using the RCP8.5 climate forcing scenario. For our analyzed climate fields, we utilize output spanning 1986-2100. Over this time period, the CESM-LE simulates forty ensemble members with the same underlying physics, but each member's air temperature fields are given slightly differing initial conditions, providing a tool to assess the role of internal variability in climate change projections. By applying our analysis across ensemble members, we can analyze both the forced climate response, represented by the ensemble mean, and internal variability, represented by the ensemble spread.

Our data-driven, causal inference approach applies time series analysis to the CESM-LE model output, where the variables of interest are simultaneously represented in a large, inclusive network for each ensemble member. Causal network input consists of ten spatially averaged time series, which track various aspects of the high-latitude climate system. Each variable and its spatial averaging domain is listed in Table 1. Four atmospheric variables are used, two of which represent Arctic temperatures at different altitudes in the troposphere, and two that represent components of meridional energy transport into the high latitudes. Surface energy fluxes and sea-ice extent are represented by the remaining six time series variables. In this section, we provide a physical description of each term within the context of the RCP8.5 scenario.

In all ensemble members, the annual-mean Arctic warming response to RCP8.5 forcing is largest below $850 \mathrm{hPa}$, dictated primarily by changes in the wintertime vertical temperature structure (Fig. 1a). At the end of the 20th century, the Arctic is characterized by stable stratification in the boundary layer; temperature increases with height throughout the lower portion of the atmosphere in all seasons, with strong inversions occurring in winter (DJF) and spring (MAM). By the end of the 21st century, surfaceamplified warming fully erodes the boundary-layer temperature inversions in fall (SON) and winter (DJF), with winter experiencing the largest change in inversion strength. Hence, to characterize the vertically non-uniform Arctic temperature changes, our causal networks include $850 \mathrm{hPa}$ temperature $\left(T_{850}\right)$ and inversion strength variables, where inversion strength is estimated as the difference between $T_{850}$ and near-surface $(2 \mathrm{~m})$ temperature.

Changes in remotely sourced heat and moisture into the high latitudes are evaluated using the horizontal convergence of latent and sensible heat fluxes, $-\nabla \cdot L \mathbf{v} q$ and $-\nabla \cdot c_{p} \mathbf{v} T$, respectively. At a given pressure $(p)$ level, the meridional convergence of zonal mean heat flux is then given by:

$$
\begin{aligned}
-\nabla_{p} \cdot L[\overline{v q}] & =\frac{-1}{R \cos \phi} \frac{\partial}{\partial \phi}(L[\overline{v q}] \cos \phi) \\
-\nabla_{p} \cdot c_{p}[\overline{v T}] & =\frac{-1}{R \cos \phi} \frac{\partial}{\partial \phi}\left(c_{p}[\overline{v T}] \cos \phi\right)
\end{aligned}
$$

where $L$ is the latent heat of vaporization $\left(2.51 \times 10^{6} \mathrm{~J}\right.$ $\left.\mathrm{kg}^{-1}\right), c_{p}$ is the specific heat capacity of air at constant pressure $\left(1004 \mathrm{~J} \mathrm{~kg}^{-1} \mathrm{~K}^{-1}\right), v$ is meridional wind, $q$ is specific humidity, $R$ is Earth's radius, $\phi$ is latitude, brackets denote a zonal mean, and overbars denote a time average. Diagnostic variables $\overline{v q}$ and $\overline{v T}$ are calculated online during simulation at each model time step (30 minutes) to take cyclonic effects into account, then saved as monthly means. However, analogous transport terms involving geopotential height and zonal wind are not provided for CESM1-LE. Due to this data limitation, we neglect the geopotential energy contribution to dry static energy flux convergence (Eqn. 2), which contributes approximately $29 \%$ of the annual mean convergence in the Arctic troposphere (Cardinale et al. 2021). Since we use zonal means in Eqns. 1 and 2, the averaging domain for our two transport terms must be defined in terms of latitude (Table 1). Finally, we neglect the latent heat of freezing for the case of solid precipitation (Eqn. 1), following prior assessments of Arctic latent heat flux convergence in CESM1 (Graversen and Langen 2019).

Climatological, mass-weighted vertical profiles of the two heat flux convergence components, as well as their distinct responses to RCP8.5 forcing, are shown in Figure 1b,c. In the Arctic midtroposphere $(800-400 \mathrm{hPa})$, increases in latent heat flux convergence (Eqn. 1) occur in every season over the 21st century, with ensemble-mean changes on the order of $1 \mathrm{Wm}^{-2}$ (Fig. 1b). Sensible heat flux convergence (Eqn. 2) trends are largest between 950 and $600 \mathrm{hPa}$, with ensemble-mean decreases on the order of $10 \mathrm{Wm}^{-2}$ that are largest in winter and spring (Fig. 1c). The forced changes in latent heat flux convergence are more robust, despite their smaller magnitude, because the forced changes in sensible heat flux convergence lie largely within the internal variability. Taken together, midtroposphere changes reflect a large-scale response to anthropogenic forcing, where latent heat flux convergence follows a strengthened meridional humidity gradient (not shown) and sensible heat flux convergence follows a weakened meridional temperature gradient (Fig. 1a). At lower altitudes, below $800 \mathrm{hPa}$, decreases in net heat flux convergence suggest an additional influence from local surface conditions. For instance, the atmospheric response to sea-ice loss has been connected to enhanced local moisture export from the Arctic (Singh et al. 2017) and equatorward mixing of thermal anomalies over adjacent continents (Deser et al. 2010), consistent 


\begin{tabular}{|c|c|c|}
\hline Variable & Vertical Domain & Horizontal Domain \\
\hline Sensible Heat Flux Convergence $\left(-\nabla_{850} \cdot c_{p}[\overline{v T}]\right)$ & $850 \mathrm{hPa}$ & $70^{\circ}-90^{\circ} \mathrm{N}$ \\
\hline Latent Heat Flux Convergence $\left(-\nabla_{500} \cdot L[\overline{v q}]\right)$ & $500 \mathrm{hPa}$ & $70^{\circ}-90^{\circ} \mathrm{N}$ \\
\hline Boundary Layer Atmospheric Temperature $\left(\mathrm{T}_{850}\right)$ & $850 \mathrm{hPa}$ & 1986-1996 annual mean sea-ice edge ( $15 \%$ concentration contour) \\
\hline Boundary Layer Inversion Strength & $\mathrm{T}_{850}-\mathrm{T}_{2 \mathrm{~m}}$ & 1986-1996 annual mean sea-ice edge ( $15 \%$ concentration contour) \\
\hline Net All-Sky Longwave Radiative Flux ( $\left.\mathrm{LW}_{\text {net }}\right)$ & Surface & 1986-1996 annual mean sea-ice edge ( $15 \%$ concentration contour) \\
\hline Net All-Sky Shortwave Radiative Flux ( $\mathrm{SW}_{\text {net }}$ ) & Surface & 1986-1996 annual mean sea-ice edge ( $15 \%$ concentration contour) \\
\hline Shortwave Cloud Radiative Effect $\left(\mathrm{SW}_{\mathrm{CRE}}\right)$ & Surface & 1986-1996 annual mean sea-ice edge ( $15 \%$ concentration contour) \\
\hline Longwave Cloud Radiative Effect ( $\left.\mathrm{LW}_{\mathrm{CRE}}\right)$ & Surface & 1986-1996 annual mean sea-ice edge ( $15 \%$ concentration contour) \\
\hline Turbulent Heat Flux & Surface & 1986-1996 annual mean sea-ice edge ( $15 \%$ concentration contour) \\
\hline Sea-Ice Extent & Surface & 1986-1996 annual mean sea-ice edge ( $15 \%$ concentration contour) \\
\hline
\end{tabular}

TABLE 1. List of the causal network input variables described in Section 2a, along with the spatial averaging region used for each time series. Where relevant, parenthesized variable names denote abbreviations used in subsequent figures. Note that turbulent heat flux is defined as the sum of sensible and latent heat flux at the surface.

with the change from sensible heat flux convergence to divergence in winter under RCP8.5 forcing (Fig. 1c). We aim for our causal networks to evaluate changes in heat and moisture at heights where RCP8.5 trends are largest. The networks therefore employ time series of latent heat flux convergence at $500 \mathrm{hPa}$ and sensible heat flux convergence at $850 \mathrm{hPa}$. For both components, Arctic heat flux convergence is defined as the average over $70^{\circ}-90^{\circ} \mathrm{N}$, following prior research on atmospheric energy transport in CESM1 (Graversen and Langen 2019).

Sea-ice extent is defined in terms of its total Northern Hemisphere surface area, which is calculated as an area-weighted sum of grid cell sea-ice concentration. The change in sea-ice extent over the 21st century is shown in Figure 2a for the ensemble mean. By 2100, fall (SON) seaice coverage is completely lost in the Northern Hemisphere $\left(<0.1\right.$ million $\left.\mathrm{km}^{2}\right)$ for all ensemble members, while the central Arctic remains ice-covered in the remaining seasons. Spring (MAM) retains the largest sea-ice area in 2100 (12.3 - 14.2 million $\mathrm{km}^{2}$ ), largely due to slower melt rates relative to summer (JJA) and winter (DJF). To coherently assess the atmospheric response to sea-ice loss, all surface and lower-tropospheric variables are averaged over ocean areas with at least 15\% sea ice in the 1986-1996 annual mean (black line, Fig. 2). This limitation excludes high-latitude regions that are perennially ice free at the start of the 21 st century, but includes areas that become seasonally ice free under RCP8.5 forcing (blue regions, Fig. 2a). All regimes within this spatial domain feature an increase in surface heat uptake in summer (JJA, Fig. 2b) and release to the atmosphere in fall and winter (SON and DJF, Fig. 2b). Decreases in inversion strength closely follow the increases in upward surface heat flux (SON and DJF, Fig. 2c), which occur poleward of the climatological ice edge. Significant inversion strength changes thus take place over both regions that are ice-covered (i.e., the central Arctic) and ice-free (i.e., Hudson Bay) by 2100. This spatial pattern of surface and lower-tropospheric changes are robust across ensem- ble members and across smaller thresholds for defining the ice line (5\% and $10 \%$, not shown).

For the causal network inputs listed in Table 1, the surface energy budget is described using five variables. The sum of surface sensible and latent turbulent heat fluxes provide the first surface variable, upward turbulent heat flux. The second and third surface time series represent the shortwave radiation budget: net shortwave radiative flux at the surface and shortwave $\left(\mathrm{SW}_{\text {net }}\right.$ ) cloud radiative effect $\left(\mathrm{SW}_{\mathrm{CRE}}\right)$, with the latter quantity calculated as the difference between all-sky and clear-sky net surface shortwave flux. Net longwave surface flux $\left(\mathrm{LW}_{\text {net }}\right)$ and cloud radiative effect $\left(\mathrm{LW}_{\mathrm{CRE}}\right)$ are calculated similarly to the shortwave variables, where a positive $\mathrm{LW}_{\mathrm{CRE}}$ is a surface warming tendency, consistent with the climatological effect of Arctic clouds. Throughout this study, all surface energy budget terms are defined as positive down (into the surface).

\section{b. Causal Networks}

Causal networks are constructed from the ten aforementioned time series, using a linear application of Pearl's causal effect theory (Pearl 2013; Runge et al. 2015). To compare the impact of local and remote warming sources simultaneously, we must select a temporal resolution that accommodates both the short (daily) timescale of variability for midtroposphere heat flux convergence, as well as the longer (monthly) timescale of variability for Arctic sea-ice extent. We find that averaging daily CESM-LE output into weekly (i.e., quarter-monthly, as in Kretschmer et al. (2016)) timesteps best accomplishes this goal. Assessing causal relationships also requires stationary time series input, so we next remove the anthropogenic trend from each variable. The trend is estimated as a second-order polynomial and subtracted from the data, applied separately for each week in the seasonal cycle. Then, each variable is divided by its standard deviation. The resulting time series input consists of weekly standardized anomalies with 

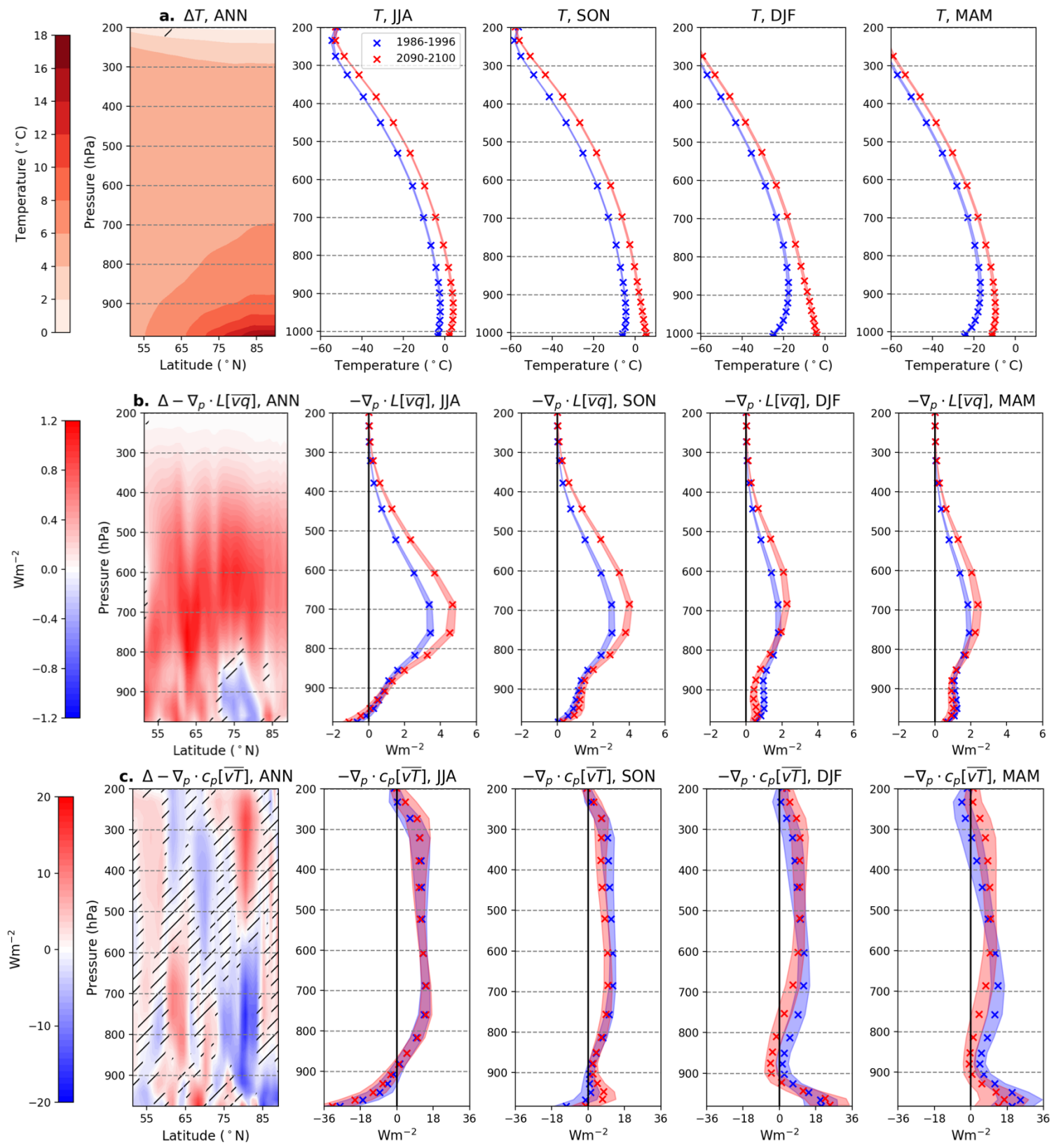

FIG. 1. The 21 st century, RCP8.5-forced change in (a) atmospheric temperature (T), (b) zonal-mean latent heat flux convergence $\left(-\nabla_{p} \cdot L[\overline{v q}]\right)$, and (c) zonal-mean sensible heat flux convergence $\left(-\nabla_{p} \cdot c_{p}[\overline{v T}]\right)$ in the Community Earth System Model, Large Ensemble (CESM-LE).The leftmost column shows the extratropical zonal-mean, annual-mean difference between the 2090-2100 and 1986-1996 climatologies, where color represents the ensemble-mean change, and hatching represents regions where the forced change is insignificant compared to internal variability (two-sided Student's t-test, $p=0.05$ ). The remaining columns show the Arctic-average (as defined in Table 1) climatologies in 1986-1996 (blue) and 2090-2100 (red) for each season, where x's indicate the ensemble mean and envelopes indicate the ensemble spread ( $\pm 2 \sigma)$. In (b) and (c), heat flux convergences are mass-weighted by the pressure thickness $\left(\frac{d p}{g}\right)$ at each model level (hybrid sigma coordinates).

constant mean and variance, shown in Figure 3 for a characteristic ensemble member. Temporal periodicity remains present when there are large seasonal differences in the magnitude of anomalies, which is especially apparent in the shortwave surface fluxes (Fig. 3f,g). This seasonality is a key consideration throughout our analysis. In general, anomalies are an order of magnitude smaller than $\mathrm{CO}_{2}$ forced trends over 1986-2100. Sensible heat flux convergence (Fig. 3a) is the one exception to this relationship, as its 21 st century trends are smaller than its anomalies. The process of constructing causal networks from these time series occurs in two phases. First, we identify the robust, 


\section{a. Climatological Sea-Ice Extent}
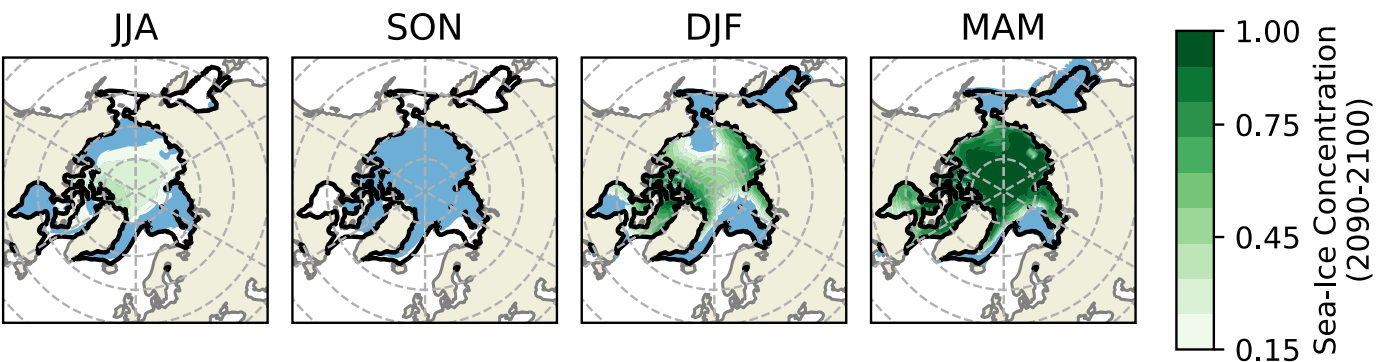

\section{b. Change in Surface Heat Flux}
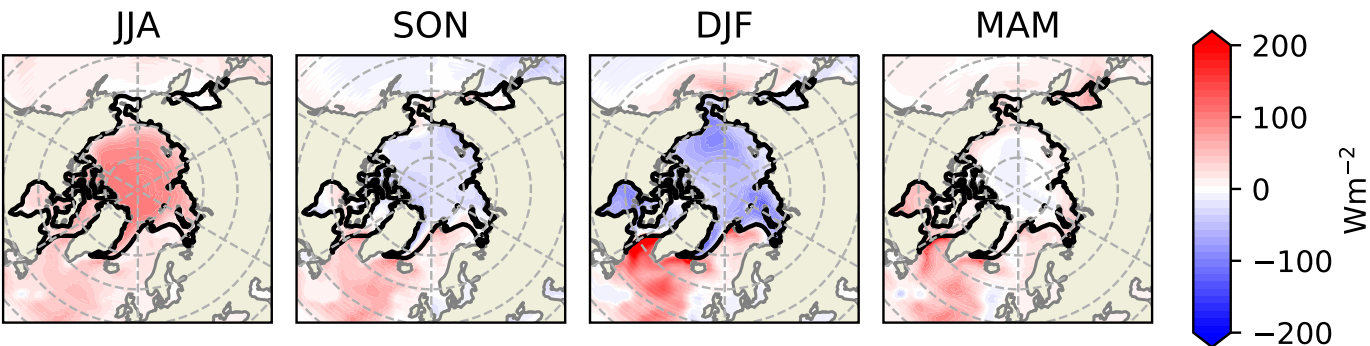

\section{c. Change in Inversion Strength}
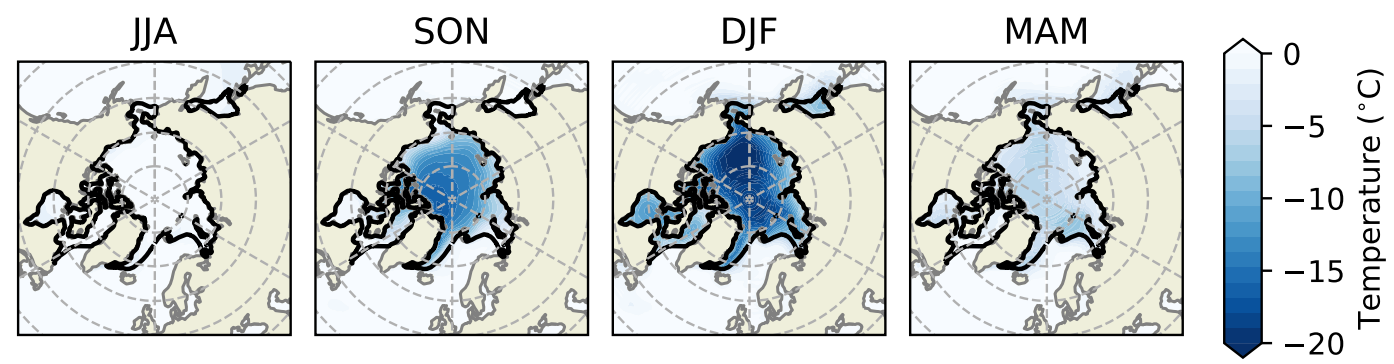

FIG. 2. The 21st century, RCP8.5-forced change in (a) sea-ice extent, (b) net surface heat flux $\left(\mathrm{SW}_{\text {net }}-\mathrm{LW}_{\text {net }}\right.$ - Turbulent Heat Flux; positive down), and (c) boundary layer inversion strength $\left(\mathrm{T}_{850}-\mathrm{T}_{2 \mathrm{~m}}\right)$ over ocean regions in the Community Earth System Model, Large Ensemble (CESM-LE). In all maps, the black line represents the annual mean, ensemble mean sea-ice edge at the start of the study period (1986-1996), which corresponds to the spatial averaging domain defined in rows 3-10 of Table 1. In (a), the 2090-2100 ensemble-mean climatological sea-ice concentration is shown with green contours for each season. Blue regions indicate where seasonal sea ice concentrations are greater than $15 \%$ in the 1986-1996 climatology. In (b) and (c), ensemble mean changes in surface heat flux (b) and inversion strength (c) are shown as the difference between the 2090-2100 and 1986-1996 climatologies. Latitude circles (dashed) are shown in $10^{\circ}$ intervals for $50^{\circ}-90^{\circ} \mathrm{N}$.

time-lagged causal relationships between each variable in a CESM ensemble member. Then, we quantify causal effects using a linear vector autoregressive (VAR) model.

Causal links between each variable are identified using the PC-algorithm adapted for time series, named after its creators Peter Spirtes and Clark Glymour (PC-Stable, Spirtes et al. 2000). For each input variable, the algorithm begins by calculating every possible time-lagged linear auto-correlation and cross-correlation over a predetermined time window, or maximum lag $\left(\tau_{\max }\right)$. The linear lagged correlation measure is defined as:

$$
\rho\left(X_{i}(t-\tau), X_{j}(t)\right)
$$

where $\rho$ is the Pearson correlation coefficient, $\tau$ is a time lag (weeks), $X_{j}(t)$ is one of the ten input time series variables defined in Section 2a, and $X_{i}(t-\tau)$ are lagged time series with a potential causal influence on $X_{j}(t)$. Contemporaneous links are not considered in this study. The significance of $\rho$ is assessed with a pre-defined significance threshold, $\alpha$, and if $\rho$ is found to be insignificant, then we conclude that $X_{i}(t-\tau)$ does not cause $X_{j}(t)$ and remove it from the set of possible links. We test several values for $\alpha$ and find $\alpha=0.01$ provides the optimal balance between network simplicity and network connectivity. Our choices for $\tau_{\max }$ are discussed in Section $3 \mathrm{a}$. 
Causal Network Input

Anomalies

$$
-\nabla_{850} \cdot c_{p}[\overline{v T}]
$$

a.

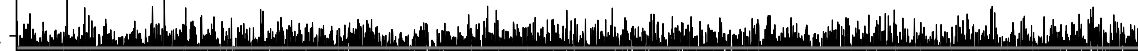

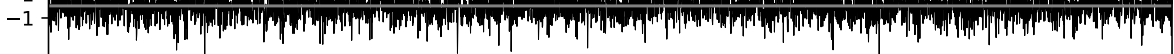

b.

$$
-\nabla_{500} \cdot L[\overline{v q}]
$$

1 -

$$
-1-1
$$

c.

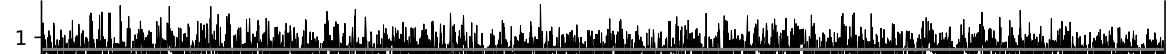

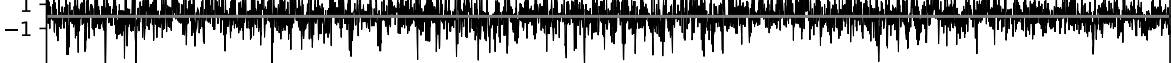

d.

Inversion Strength

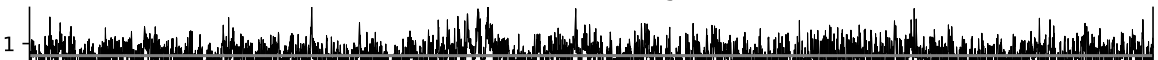

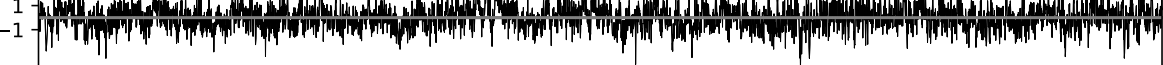

e.

$\mathrm{LW}_{\text {net }}$

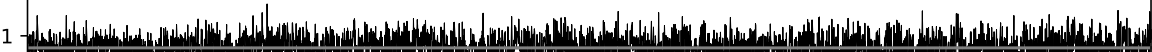
-1 -

f.

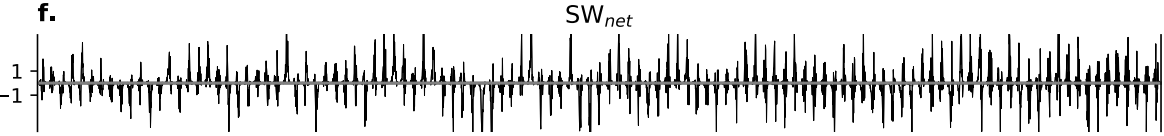

\section{g.}

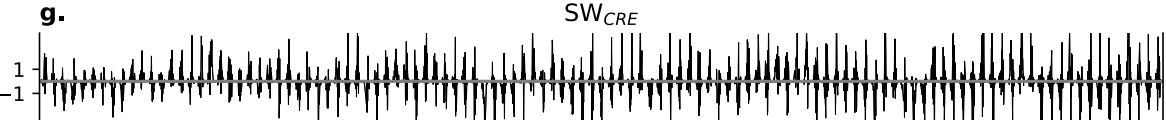

h.

LW

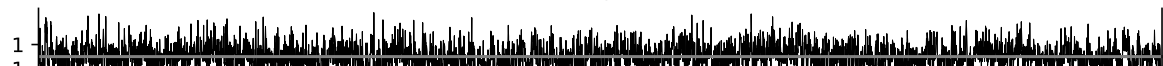

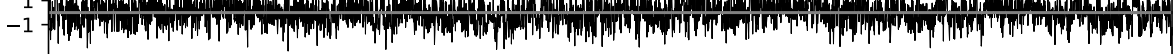

i.

Turbulent Heat Flux

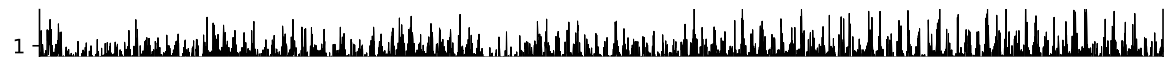
-1 -

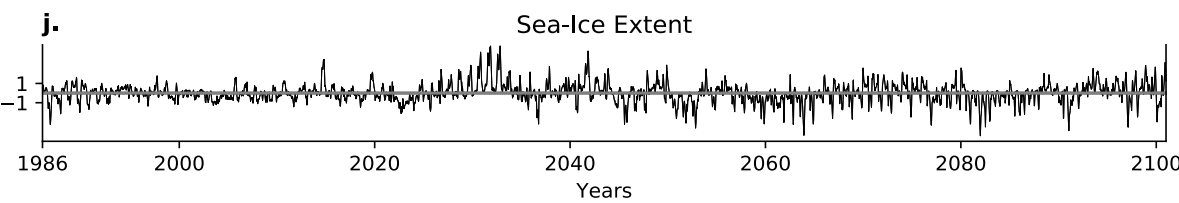

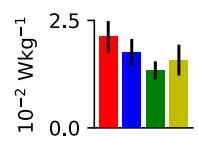
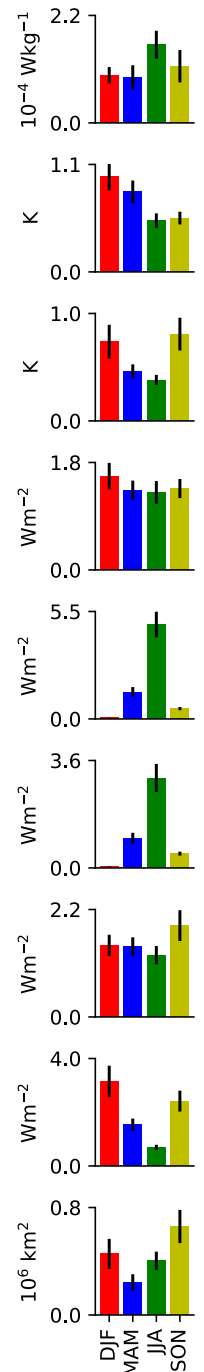

Trends
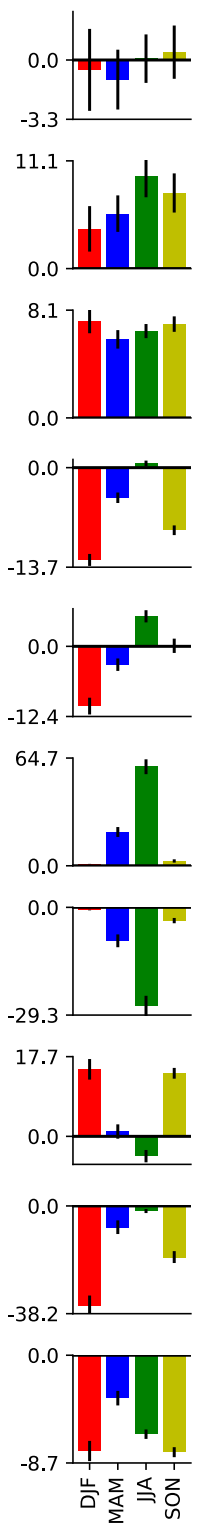

FIG. 3. Weekly time series of causal network inputs, standardized and detrended, shown for a characteristic ensemble member in the Community Earth System Model, Large Ensemble (CESM-LE). Rows a-j represent the spatially averaged variables defined in Table 1. For each variable, barplots display the magnitude of ensemble-mean $1 \sigma$ anomalies and RCP8.5 trends (1986-2100) for each season. Barplot errorbars represent the ensemble spread, calculated as in Figure 1. Trends in all surface energy budget terms (rows e-i) are signed positive down (into the surface). Note that mass weighting is not applied to sub-monthly heat flux convergences (rows a and b), so trends and anomalies are shown in $\mathrm{W}$ kg $\mathrm{g}^{-1}$. Products $\overline{v q}$ and $\overline{v T}$ are calculated as weekly averages from daily diagnostic output for $v, q$, and $T$ at $850 \mathrm{hPa}$ and $500 \mathrm{hPa}$.

While $X_{i}(t-\tau)$ may be unconditionally correlated with $X_{j}(t)$, the relationship could be confounded by the influence of another network variable. Therefore, after the initial lagged correlation test, the PC-algorithm tests the remaining significant links a second time, conditioned on the influence of a third process, $Z_{1}$ :

$$
\rho\left(X_{i}(t-\tau), X_{j}(t) \mid Z_{1}\right)
$$

where $Z_{1} \neq X_{i}(t-\tau)$ is the auto or cross-link possessing the strongest unconditional correlation with $X_{j}(t)$ in Eqn. 3. 
The vertical line in Eqn. 3 denotes removing the linear influence of $Z_{1}$ from both $X_{i}(t-\tau)$ and $X_{j}(t)$ and testing the correlation between their residuals. If $Z_{1}$ makes the formerly significant link insignificant, the two variables are said to be conditionally independent, and the link is subsequently removed. This process is repeated over $n$ iterations by adding an increasingly stringent number of conditions, $Z_{2}, Z_{3}, \ldots, Z_{n}$ to the partial correlation tests until no more links can be removed. The PC-algorithm finishes when it converges to a final set of significant links for each variable, which are subsequently considered the causes of $X_{j}(t)$. This designation is based on the causal Markov condition, which states that $X_{j}$ is independent of all network variables, except $X_{j}$ 's effects, when conditioned on the causes of $X_{j}$ (Spirtes et al. 2000). The PC-algorithm thus accounts for all indirect and confounding causal connections in the complex network, assuming all relevant variables for the system are included. This assumption, which is usually violated to some degree in practice, emphasizes the importance of the variable selection process, as well as the need for prior physical knowledge about the system in question.

Finally, after uncovering each variable's causal predictors with the PC-algorithm, we quantify causal effects following Runge et al. (2015), using a VAR model:

$$
\mathbf{X}(t)=\sum_{\tau=1}^{\tau_{\max }} \Phi(\tau) \mathbf{X}(t-\tau)+\epsilon_{t}
$$

where $\mathbf{X}$ is a vector of shape $(N, t)$ containing time series for $N$ variables, $\Phi$ is a standardized regression coefficient matrix of shape $\left(N, N, \tau_{\max }\right)$, and $\epsilon_{t}$ are independent, identically distributed error terms, which describe the uncorrelated probability distributions of each causal network variable's anomalies (Fig. 3). An individual regression coefficient, or link coefficient, $\Phi_{j, i}(\tau)$, indicates the expected change in variable $X_{j}(t)$ caused by a hypothetical $1 \sigma$ perturbation in $X_{i}(t-\tau)$ with all other variables held constant. $\tau_{\max }$ refers to the time domain over which link coefficients are added. The VAR model defined in Eqn. 5 bears some resemblance to Green's Functions used in prior polar climate studies (Kostov et al. 2017), which quantify a climate variable's response to a hypothetical step-increase in a given forcing. However, Eqn. 5 additionally utilizes causal inference to account for coupled interactions modulating the response. For instance, $\Phi_{j, i}(\tau)=0$ unless $X_{i}(t-\tau)$ causes $X_{j}(t)$, as determined by the PC-algorithm. This key feature of matrix $\Phi$ frees the VAR model from having to fit negligible parameters, thus allowing it to accommodate a large number of variables. The link coefficient structure in $\Phi$ also serves as the causal network, tracing pathways between an imposed perturbation to any variable and the expected temperature response. We construct these networks for each CESM ensemble member using Eqns. 3-5, then analyze their structure to understand the causes of the Arctic's changing temperature inversion.
A visual schematic of a causal network, as well as its associated causal effects, is shown in Figure 4. The total causal effect $(\mathbf{T C E}(\tau))$ of any hypothetical perturbation is calculated by iteratively computing link coefficient matrix products from a causal network ( $\Phi$, Eqn. 5), given by:

$$
\operatorname{TCE}(\tau)=\sum_{s=1}^{\tau} \Phi(s) \operatorname{TCE}(\tau-s) .
$$

$T C E_{j, i}(\tau)$ represents the total causal effect of perturbed variable $\left(X_{i}(t-\tau)\right)$ on a response variable $\left(X_{j}(t)\right)$. It should be noted that the structure of Eqn. 5 and Eqn. 6 are similar. Eqn. 5 is a full description of the causal network, where regression coefficients are calculated from 1 to $\tau_{\max }$. Eqn. 6 highlights that causal effects can be calculated for any lag in the network, where each effect is the sum of regression coefficients up to (and only to) that specified time lag. We also use this framework to isolate the portion of a causal effect mediated by an intermediate network variable, defined as $X_{k}$. This calculation is accomplished by first setting all link coefficients through $X_{k}$ to zero in matrix $\Phi$ (Eqn. 5), resulting in a modified coefficient matrix, $\Phi^{k}$. We then repeat the total causal effect calculation (Eqn. 6) with this modified matrix. The difference between the modified and unmodified calculations yields the mediated causal effect, defined as:

$$
M C E_{j, i}^{k}(\tau)=T C E_{j, i}(\tau)-T C E_{j, i}^{k}(\tau)
$$

where $M C E_{j, i}^{k}(\tau)$ represents the causal effect of $X_{i}(t-\tau)$ on $X_{j}(t)$ mediated by network variable $X_{k}$. Note that $M C E_{j, i}^{k}(\tau)$ is equal to $T C E_{j, i}(\tau)$ if $X_{k}=X_{j}$. Relatedly, if $X_{k}=X_{i}$, then $M C E_{j, i}^{k}(\tau)$ indicates the contribution of autocorrelation (memory) in the perturbation of $X_{i}$.

\section{Results}

\section{a. The Causal Effect of Enhanced Arctic Heat Flux Con- vergence and Sea-Ice Loss}

In our causal networks, we track remote Arctic warming sources by imposing a hypothetical $+1 \sigma$ step increase in $500 \mathrm{hPa}$ Arctic latent heat flux convergence $\left(-\nabla_{500} \cdot L[\overline{v q}]\right)$ and a $-1 \sigma$ step decrease in sensible heat flux convergence $\left(-\nabla_{850} \cdot c_{p}[\overline{v T}]\right)$, with the sign of the perturbations reflecting 21 st century anthropogenic trends (Fig. 1b,c). Similarly, a $-1 \sigma$ step decrease in sea-ice extent is used to track the local impact of sea-ice loss. The magnitude of perturbations is equivalent to the annual standard deviation of each detrended time series variable. The total causal effect of each perturbation on $850 \mathrm{hPa}$ Arctic temperature and inversion strength is shown in Figure 5. To account for the seasonality of Arctic warming, we calculate these causal effects after four separate implementations of the PC-algorithm, where the response variables $(850 \mathrm{hPa}$ 


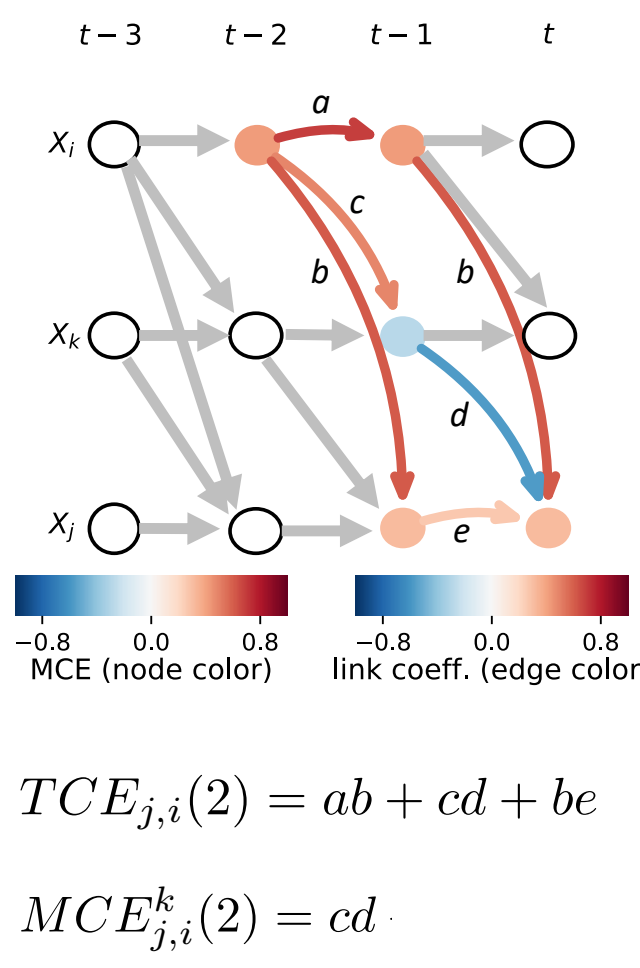

FIG. 4. Schematic of a causal network time series graph, as introduced in Runge et al. (2015). Causal pathways are defined by the set of all arrows (gray and colored) and are quantified as the regression coefficient matrix of a VAR model ( $\Phi$, Eqn. 5) with $N=3$ variables $\left(X_{i}, X_{k}, X_{j}\right)$ and $\tau_{\max }=3$ weeks. Curved, colored arrows denote the specific pathways used to quantify the total causal effect of $X_{i}(t-2)$ on $X_{j}(t)\left(T C E_{j, i}(2)\right.$, Eqn. 6) and the causal effect mediated by intermediate variable $X_{k}\left(M C E_{j, i}^{k}(2)\right.$, Eqn. 7). In this example, the link coefficient pathway quantifying MCE (cd, blue node at $X_{k}(t-1)$ ) reduces the magnitude of TCE $(a b+c d+b e)$ because the effects are opposite in sign. Many potential causal links aren't shown, as they are deemed insignificant by the PC algorithm (Eqs. 3 and 4) and excluded from the causal network, such as $X_{j}$ causing $X_{k}$ at any lag. Note that the color of affected nodes is constant for each variable (row), as it corresponds to MCE solely for the lag where the perturbation is initiated ( $\mathrm{t}-2$, in this case).

temperature or inversion strength) are masked to only include data from summer (JJA), fall (SON), winter (DJF), and spring (MAM), respectively, following the approach of (Kretschmer et al. 2016). Network regression coefficients are fit for each season using Eqns. 3-5. Then, causal effects are calculated at each time lag using Eqn. 6. The causal effects analyzed in this section represent the time-lagged linear response of Arctic temperatures to an instantaneous step change in sea ice and/or poleward heat transport. Given the use of detrended time series data, these hypothetical step changes do not describe the transient temperature response to $\mathrm{CO}_{2}$-forced changes. However, they nonetheless offer the advantage of isolating the impact of individual processes on the lower troposphere in a fully coupled setting.

In Figure 5a, the total causal effect of enhanced latent heat flux convergence $\left(+1 \sigma-\nabla_{500} \cdot L[\overline{v q}]\right)$ is shown at lags of one to four weeks ( $\tau=1$ to $\tau_{\max }=4$ ) for each CESM ensemble member, where our choice of $\tau_{\max }$ follows the observed timescale of moist intrusions into the Arctic (Woods et al. 2013). One week following a $+1 \sigma$ step increase in latent heat flux convergence, the Arctic atmosphere responds by warming at $850 \mathrm{hPa}$ in all seasons (black curves), with the total causal effect $\left(T C E_{j, i}(1)\right)$ ranging from $.077 \mathrm{~K}$ in summer to $.25 \mathrm{~K}$ in winter for the ensemble mean. This response then quickly decays in the subsequent three weeks, reflecting the short timescale of the atmospheric perturbation. The initial warming impact at $850 \mathrm{hPa}$ is robust, being detected in all forty CESM ensemble members. A similarly robust impact on boundary-layer inversion strength (green curves) is found in summer, fall, and winter. In summer, the inversion's response to latent heat flux convergence is similar to the $850 \mathrm{hPa}$ temperature response, which indicates little-to-no warming near the surface. In summer, it is likely that an anomalous downward longwave radiation flux to the surface, associated with the 850 $\mathrm{hPa}$ temperature change, goes into sea-ice melt rather than warming. This mechanism is further detailed in the following section. In fall and winter, however, the initial ( $\tau$ $=1$ ) positive inversion strength response is weaker than the $850 \mathrm{hPa}$ temperature response. Furthermore, after four weeks $(\tau=4)$, the inversion strength response switches from positive to weakly negative in some CESM ensemble members, especially in winter. This change in sign implies that a secondary warming response to latent heat flux convergence appears near the Arctic surface. The near-surface warming response begins weaker than the $850 \mathrm{hPa}$ warming response, but eventually exceeds $850 \mathrm{hPa}$ warming after four weeks. This fall/winter temperature response follows a similar timeline to prior observation-based studies of Arctic moist intrusions (Woods and Caballero 2016): the temperature response is initially slower at the surface than in the troposphere, but the situation eventually reverses. Such related studies have focused strictly on strong, highly localized moist intrusions, which produce surface temperature anomalies up to an order of magnitude larger than the warming tracked by our causal effect networks. The moist transport perturbations in this study are less strictly defined, as our networks track the response to any positive anomaly in Arctic-averaged latent heat flux convergence at $500 \mathrm{hPa}$. In spring, the inversion strength response to latent heat flux convergence is weak or insignificant (i.e., zero), with causal effects detected in only half of CESM ensemble members.

The total causal effect of weakened sensible heat flux convergence is shown in Figure $5 \mathrm{~b}\left(-1 \sigma-\nabla_{850} \cdot c_{p}[\overline{v T}]\right)$ for the same time lags. In all seasons, fewer ensemble 

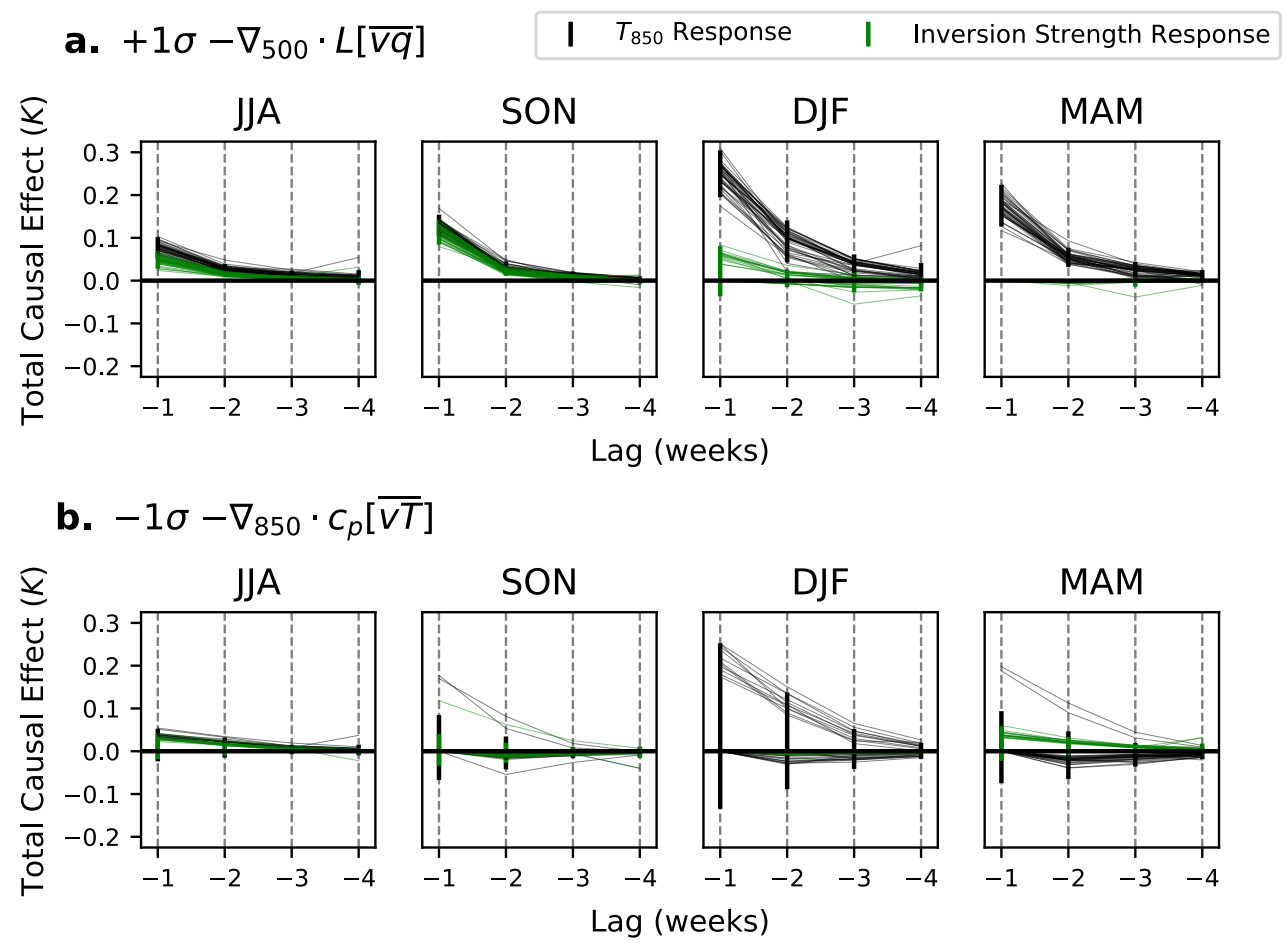

\section{c. $-1 \sigma$ Sea-Ice Extent}
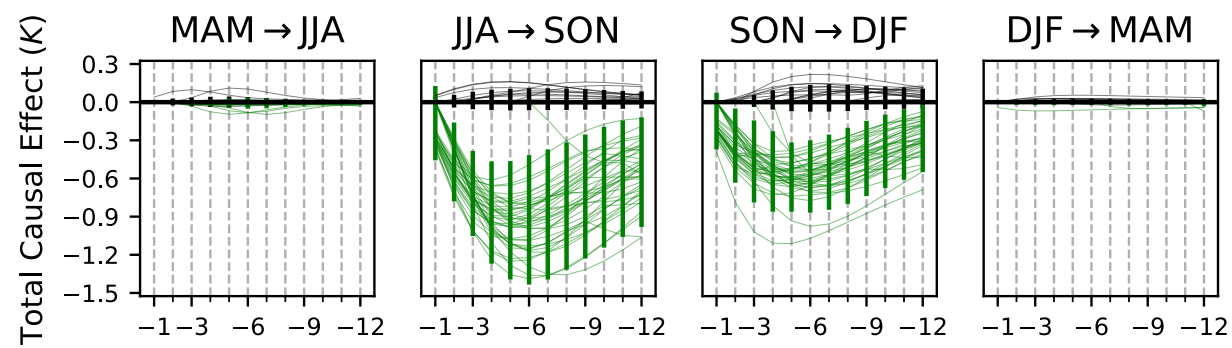

Lag (weeks)

FIG. 5. The predicted change in Arctic atmospheric temperature caused by (a) an imposed $+1 \sigma$ step increase in $500 \mathrm{hPa}$ Arctic latent heat flux convergence $\left(-\nabla_{500} \cdot L[\overline{v q}]\right)$, (b) a $-1 \sigma$ step decrease in $850 \mathrm{hPa}$ sensible heat flux convergence $\left(-\nabla_{850} \cdot c_{p}[\overline{v T}]\right)$, and (c) a $-1 \sigma$ step decrease in sea-ice extent. In (a) and (b), the $850 \mathrm{hPa}$ temperature response $\left(T_{850}\right.$, black) and boundary-layer inversion strength response (green) are shown for perturbations at one to four week lags in summer (JJA), fall (SON), winter (DJF) spring (MAM). In (c), the temperature responses are shown for perturbations at one to twelve week lags, across each seasonal transition (note the different y-axis scaling). Curves display the causal effects for individual ensemble members, if they are non-zero. At each time lag, vertical error bars denote the spread in estimated causal effect $( \pm 2 \sigma)$ across 40 CESM ensemble members, where insignificant causal effects are defined as zero.

members detect a significant causal impact on Arctic temperatures, and the significant causal effects are generally smaller in magnitude and inconsistent in sign. For instance, 11 out of 40 ensemble members detect a wintertime 850 $\mathrm{hPa}$ warming response to weakened sensible heat flux convergence, while the remaining ensemble members detect a cooling effect or no effect at all. The causal effect signal is even weaker if sensible heat transport is instead evaluated in the midtroposphere instead of at $850 \mathrm{hPa}(-1 \sigma$ $-\nabla_{500} \cdot c_{p}[\overline{v T}]$, Fig. S1). Sensible heat flux convergence anomalies only cause robust temperature changes when they are evaluated on shorter (daily) timescales, where, with the exception of spring (MAM), decreases in sensible heat flux convergence partially compensate the oppositesigned impacts of a latent heat flux convergence increase (Fig. S2). Therefore, our networks suggest that Arctic sensible heat flux convergence anomalies have small impacts on lower-tropospheric temperature on sub-monthly timescales. Instead, temperatures are more sensitive to the latent component (Fig. 5a). This result is somewhat counterintuitive, given the relative magnitudes of climatological heat flux convergences (Fig. 1b,c). However, prior energy budget analyses have suggested that latent energy transport influences Arctic climate more strongly than dry 
static energy transport (Graversen and Burtu 2016; Yoshimori et al. 2017). The total causal effects shown in Figure $5 \mathrm{a}, \mathrm{b}$ are consistent with these findings and are robust to tests that use a more equatorward spatial averaging boundary $\left(60^{\circ}-90^{\circ} \mathrm{N}\right.$, Fig. S3). The mechanism determining the differential warming impacts are explored in Section $3 b$.

We expect a $-1 \sigma$ step decrease in sea-ice extent to influence Arctic temperatures over a longer time range compared to the atmospheric perturbations in Figure 5a,b. We therefore calculate the total causal effect of sea-ice loss over a longer range of time lags, up to twelve weeks $\left(\tau_{\max }=12\right)$. Since more time elapses between a hypothetical sea-ice perturbation and the expected Arctic warming response, causal networks with $\tau_{\max }=12$ capture the influence of sea-ice loss across seasons. This interseasonal influence is shown with the total causal effects in Figure 5c. Here, most CESM ensemble members detect causal effects from sea-ice loss in the summer-to-fall (JJA $\rightarrow \mathrm{SON}$ ) and fallto-winter $(\mathrm{SON} \rightarrow \mathrm{DJF})$ transitions, demonstrating a link between fall/winter Arctic temperature changes and seaice loss in the preceding melt season. During these seasonal transitions, the Arctic warming response to sea-ice loss peaks four-six weeks after the imposed perturbation, where ensemble-mean $850 \mathrm{hPa}$ temperature changes are comparable in magnitude to those caused by enhanced latent heat flux convergence (Fig 5a). However, the causal effect of sea-ice loss at $850 \mathrm{hPa}$ is dwarfed by concurrent decreases in boundary-layer inversion strength, with total causal effects at $\tau=6$ ranging from $0.5 \mathrm{~K}-1.5 \mathrm{~K}$. The inversion strength response indicates a larger warming response to sea-ice loss near the surface. Similar results are obtained when testing causal effects at coarser time resolution ( $\tau_{\max }=12$ months, not shown), where causal effects are largely confined to lags of 1-4 months, consistent with Figure 5c.

In summary, the perturbations imposed to our causal networks demonstrate that $850 \mathrm{hPa}$ warming is caused by both sea-ice loss (Fig. 5c) and enhanced latent heat flux convergence in the Arctic midtroposphere (Fig. 5a). All else being equal, 850 -hPa warming increases the strength of the Arctic's boundary-layer temperature inversion. However, these causal effects are outweighed by strong near-surface warming caused primarily by sea-ice loss in the melt season, which weakens the temperature inversion in fall and winter. Even though anthropogenic trends are removed from our network time series, the seasonality of the total causal effects in Figure 5 are similar to the seasonality of surface-amplified warming under RCP8.5 forcing (Fig. 1a). The inversion strength response to $-1 \sigma$ sea-ice perturbations is approximately an order of magnitude smaller than the twenty-first century changes simulated in CESM1-LE (Fig. 5c, Fig. 3d), but this difference is consistent with sea-ice perturbations being similarly small in comparison to projected sea-ice loss (Fig. 3j). The causal effects therefore suggest that the Arctic vertical warming structure shown in Figure 1a can be produced by the cumulative impact of seasonal sea-ice retreat over many years, until the Arctic becomes ice free. Similarly, projected twentyfirst century increases in midtroposphere latent heat flux convergence are approximately a factor of five larger than imposed causal network perturbations (Fig. 3b), implying that the cumulative impact of many moist transport events are a significant driver of Arctic temperature trends at 850 $\mathrm{hPa}$, especially in winter and spring (Fig. 5a, Fig. 3c).

Finally, it is important to note that the spatial domain of our causal networks includes both ice-covered and iceretreat regions at the end of the 21st century (Fig 2a). Accordingly, we additionally explore the extent to which the inversion strength response to sea-ice loss is related to weaker inversions over sea ice or to the exposure of newly open ocean. We test the sensitivity of our causal effects to open-ocean exposure by assessing sea-ice loss over ice-covered and ice-retreat regimes only (Fig. S4). The sensitivity test shows that weaker inversions do occur over sea ice, and do not require the appearance of open ocean. This result is consistent with related research that found positive Arctic lapse rate feedbacks over both icecovered and ice-retreat regions across CMIP5 (Boeke et al. 2020).

\section{b. The Mediating Role of Surface Energy Fluxes}

After quantifying the Arctic temperature response to causal network perturbations, we identify which parts of the surface energy budget mediate the temperature response to latent heat flux convergence and sea-ice loss, respectively. Examining these causal pathways in greater detail reveals the physical mechanisms connecting atmospheric heat transport and sea-ice loss to Arctic warming. For each perturbation introduced in section 3a, we calculate the causal effect mediated by each energy budget term. We use Eqn. 7 to identify the key mediating pathways in each causal network at $\tau_{\max }=4$ weeks for latent heat flux perturbations (corresponding to Figure 5a, Figure 6), and at $\tau_{\max }=12$ weeks for sea-ice loss perturbations (corresponding to Figure 5c, Figure 7). We focus on the most important mediating pathways, where $M C E_{j, i}^{k}(\tau)$ is non-zero for a majority $(>50 \%$ ) of CESM ensemble members. Then, we visualize the causal pathways in a directed time series graph (right-hand panels of Fig. 6 and Fig. 7), which depicts the causal structure for a characteristic ensemble member. Each ensemble member may feature distinct causal pathways that are not seen in other members. Accordingly, the best visual aid is provided by a characteristic causal network that features the most common mediating effects. We limit this analysis to the fall and winter implementations of the PC-algorithm, as these seasons feature robust causal effects from both enhanced latent heat flux convergence (Fig. 5a) and sea-ice loss (Fig. 5c). During these 
seasons, we find that causal effects of each perturbation are mediated by changes in both turbulent and longwave heat fluxes at the surface, while changes in the shortwave energy budget play no significant role.

The variables mediating the $850 \mathrm{hPa}$ temperature response to enhanced latent heat flux convergence are shown in Figure 6a,b and the variables mediating the inversion strength response are shown in Figure $6 \mathrm{c}, \mathrm{d}$ at a lag of four weeks. As noted in the previous section, the total causal effect of latent heat transport is typically positive (warming) at $850 \mathrm{hPa}$ (gray-shaded row of Fig. 6a) in both fall and winter, while the inversion strength response features both weakly positive (strengthening) and negative (weakening) causal effects across the CESM ensemble (gray-shaded row of Fig. 6c). The total response in each temperature variable is explained by the mediating impact of progressive changes in the surface longwave radiative flux and sea-ice extent. Initially, both $T_{850}$ and inversion strength feature a direct, positive response to $-\nabla_{500} \cdot L[\overline{v q}]$, which is damped by the negative autocorrelation (memory) of the atmospheric perturbation in subsequent weeks (Fig. 6b,d). Therefore, the total effect in grey shading (row 3, Fig. 6a) can be regarded as the direct impact of latent heat flux convergence on $T_{850}$, minus the negative impacts of autocorrelation (row 2, Fig. 6a) and the mediating effect of $\mathrm{LW}_{\text {net }}$ (row 4, Fig. 6a). In Figure 6c,d, the initial strengthening of the inversion is also accompanied by a reduction of net longwave cooling at the surface. The decrease in longwave cooling then causes sea ice to melt, in turn weakening the inversion strength (Fig. 6d) through near-surface warming. Consequently, after 4 weeks, near-surface warming exceeds $850 \mathrm{hPa}$ warming in a majority of CESM ensemble members, and inversion strength has decreased below its initial value (Fig. 6c).

The magnitude of the indirect causal effect on inversion strength varies by season. The distribution of mediated causal effects of sea-ice loss on inversion strength features larger (more negative) values in winter than in fall (compare green and orange distributions, Figure 6c). In other words, the total causal effect of enhanced latent heat flux convergence produces more greatly weakened temperature inversions in winter than in fall. This result suggests that latent heat transport activates a local water vapor feedback, whereby moisture increases longwave opacity in the Arctic atmosphere, warms the surface, and melts sea ice. This water vapor greenhouse effect characterizes both the reduction in net longwave surface cooling and the resultant sea-ice loss seen in Figure 6d. A minority of ensemble members additionally detect a mediating role for longwave cloud radiative effect in the causal pathways (row 7, Fig. 6a,c, effects not shown), which may represent the transition from a "radiatively clear" to a "cloudy opaque" state in the Arctic boundary layer following a moist intrusion event (as previously highlighted in Stramler et al. (2011); Yoshimori et al. (2017)).
Using the same visual representation, Figure 7 highlights the surface energy fluxes that mediate the Arctic temperature response to a sea-ice perturbation $(-1 \sigma)$ in the summer-to-fall and fall-to-winter transitions, at a lag of twelve weeks. As expected, the sea-ice perturbation features large, positive autocorrelation compared to the transport perturbation in Figure 6, and the effects are sustained through the entirety of the time domain in the causal networks. In the first week following a $-1 \sigma$ perturbation, sea-ice loss causes an increase in surface longwave cloud radiative effect $\left(\mathrm{LW}_{\mathrm{CRE}}\right)$ and upward turbulent heat fluxes (t-11, Fig. 7b), which then mediate the eventual $850 \mathrm{hPa}$ temperature response. After six weeks, these two primary mediating effects are supplemented by small changes in net longwave surface cooling and midtroposphere latent heat flux convergence (not shown). The latter effect is most likely associated with a poleward transport of moisture from marginal ice zones toward even higher latitudes, where the enhanced moisture supply originates from newly open ocean following a negative sea-ice extent anomaly. The cloud and turbulent heat flux changes typically facilitate a warming response at $850 \mathrm{hPa}$, but the ensemblemean response is weaker in the summer-to-fall transition, where a small subset of ensemble members feature weak cooling instead (orange distribution, Fig. 7a). Hence, the sign and magnitude of the $850 \mathrm{hPa}$ temperature response is strongly linked to the seasonal mediated causal effects. The seasonal difference is particularly strong for the longwave cloud radiative effect, which tends to produce more $850 \mathrm{hPa}$ cooling in the summer-to-fall transition and more $850 \mathrm{hPa}$ warming in the fall-to-winter transition. However, clouds still facilitate summer-to-fall warming in some CESM ensemble members, as is the case for the example in Figure 7b.

The weakened boundary-layer inversion response to seaice loss (Fig. 7c,d) is shaped by the same surface energy flux changes as the $850 \mathrm{hPa}$ temperature response (Fig. 7a,b), but in a different manner. In both the summer-to-fall and fall-to-winter transitions, enhanced turbulent heat fluxes and longwave cloud radiative effect serve to counteract the negative total causal effect on inversion strength (Fig. 7c). In other words, the increase in upward surface energy fluxes that accompany sea-ice loss reduce the weakening of the temperature inversion. This mediating effect is accomplished by facilitating heat transfer from the near-surface to $850 \mathrm{hPa}$, consistent with the RCP8.5-forced changes in surface heat flux shown in Figure $2 b$ and Figure $3 i$. The radiative impact of clouds also appears to reduce the surface-amplified warming response to sea-ice loss, despite seasonal differences in the sign and magnitude of their impact at $850 \mathrm{hPa}$ (Fig. 7a). In the following section, we attribute these seasonal differences to the vertical structure of cloud properties and associated changes in atmospheric heating rates. 


$$
\nabla_{500} \cdot L[\overline{v q}](\mathrm{t}-4) \rightarrow T_{850}(\mathrm{t})
$$

a.

b. $t-4$

$$
t-3
$$

$t-2$

$t-1$

t
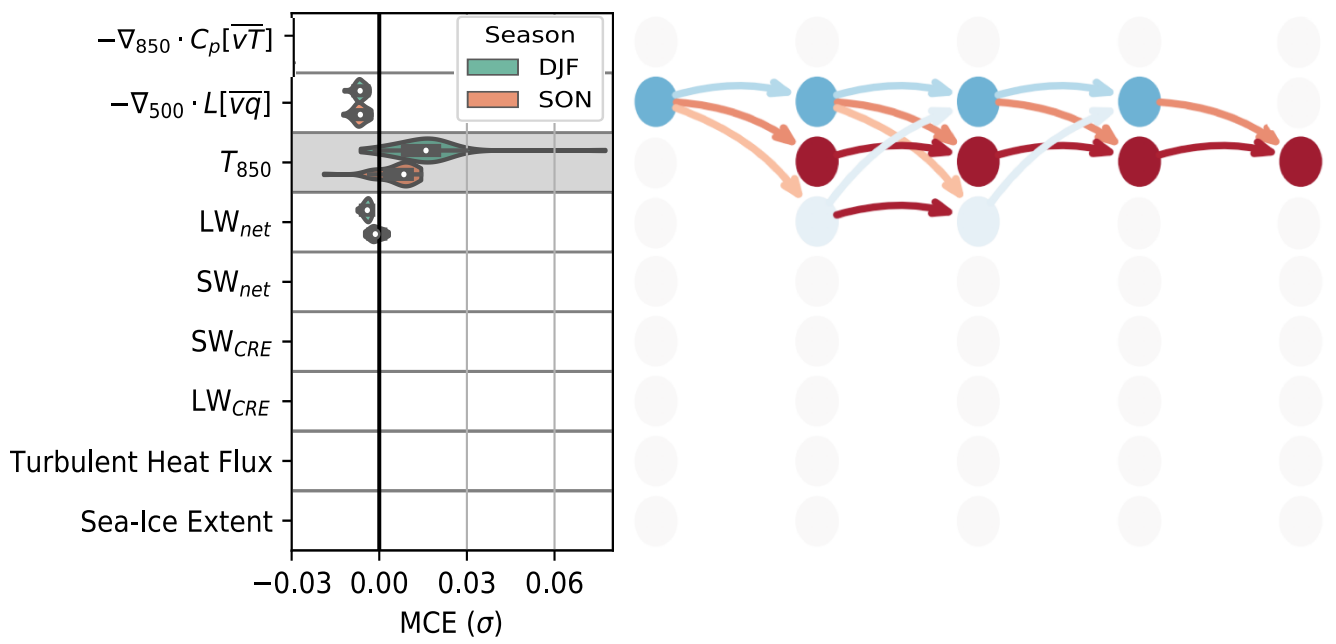

$\nabla_{500} \cdot L[\overline{v q}](\mathrm{t}-4) \rightarrow$ Inversion Strength $(\mathrm{t})$

c.

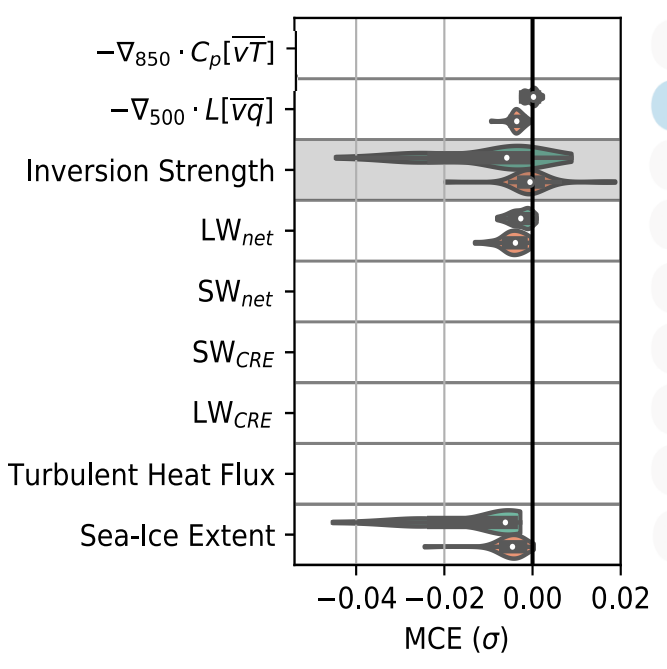

d. $t-4$

$$
t-3
$$

$t-2$ $t-1$

t

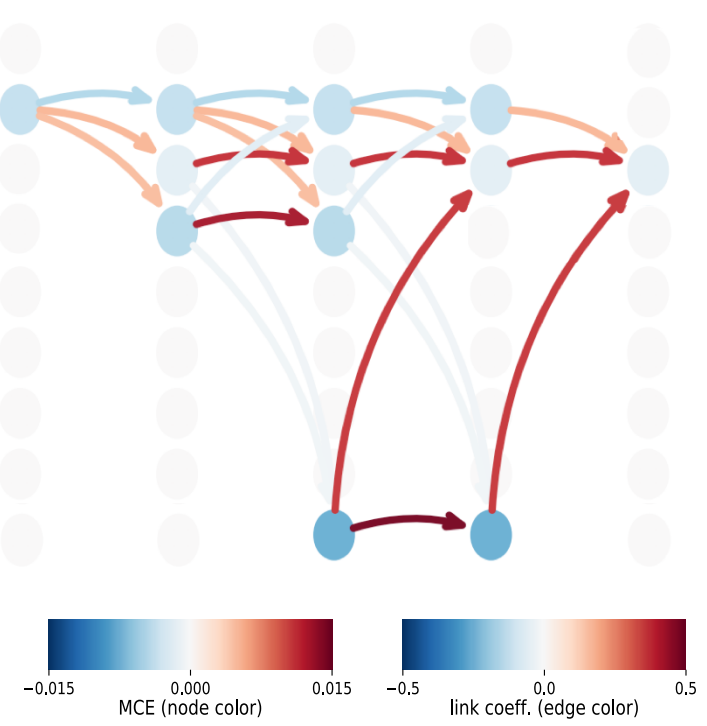

Fig. 6. Causal pathways mediating the response of $850 \mathrm{hPa}$ Arctic temperature $T_{850}(\mathrm{a}, \mathrm{b})$ and inversion strength (c,d) to an imposed $+1 \sigma$ step increase in $500 \mathrm{hPa}$ Arctic latent heat flux convergence $\left(-\nabla_{500} \cdot L[\overline{v q}]\right)$ at a lag of four weeks. Panels (a) and (c) show the distribution of mediated causal effects in fall (SON) and winter (DJF) using violin plots, where white circles indicate a median, whiskers indicate an interquartile range, and colors indicate a probability distribution function, calculated as a non-parametric kernel density estimate. Mediated causal effects are only shown if they are non-zero in a majority ( $>50 \%$ ) of CESM ensemble members. Note that causal effects mediated by $T_{850}$ and inversion strength (gray-shaded row in a,c) are equivalent to the total causal effects shown in Figure 5a at $\tau_{\max }=4$ weeks. Panels (b) and (d) illustrate mediating causal pathways in a time series graph for CESM ensemble member 12 in fall.

\section{c. Characteristics of $\mathrm{CO}_{2}$-forced Reduction in Boundary- Layer Stability}

Our causal networks reveal that Arctic boundary-layer inversions are weakened because of their sensitivity to sea-ice perturbations in the melt season, which promote surface-amplified warming (Fig. 5c, Fig. 7c). However, the magnitude of the impact also depends on associated increases in longwave cloud radiative effect and turbulent heat fluxes, which preferentially warm $850 \mathrm{hPa}$, rather than the surface, in many CESM ensemble members (Fig. 7a,b). For the final component of our analysis, we contextualize 
Sea-Ice Extent (t-12) $\rightarrow T_{850}(\mathrm{t})$

a.

b. $t-12 \quad t-11 \quad t-10 \quad t-9 \quad t-8 \quad t-7 \quad t-6 \quad t-5 \quad t-4 \quad t-3 \quad t-2 \quad t-1 \quad t$

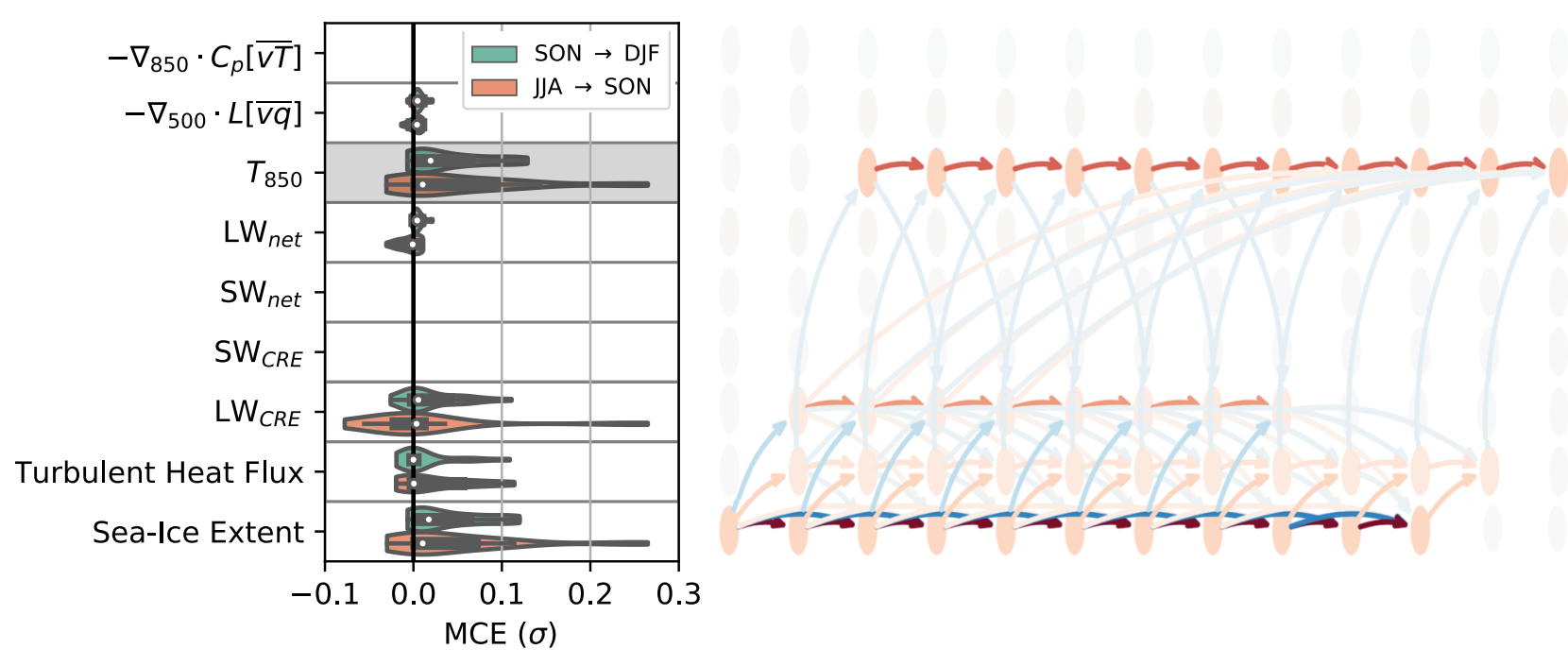

Sea-Ice Extent (t-12) $\rightarrow$ Inversion Strength (t)

C.

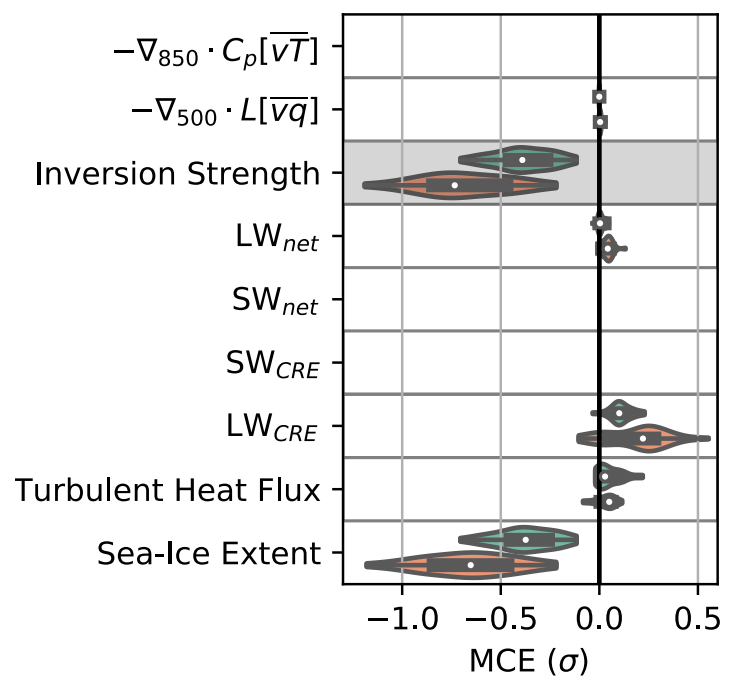

d. $t-12 \quad t-11 \quad t-10 \quad t-9 \quad t-8 \quad t-7 \quad t-6 \quad t-5 \quad t-4 \quad t-3 \quad t-2 \quad t-1 \quad t$

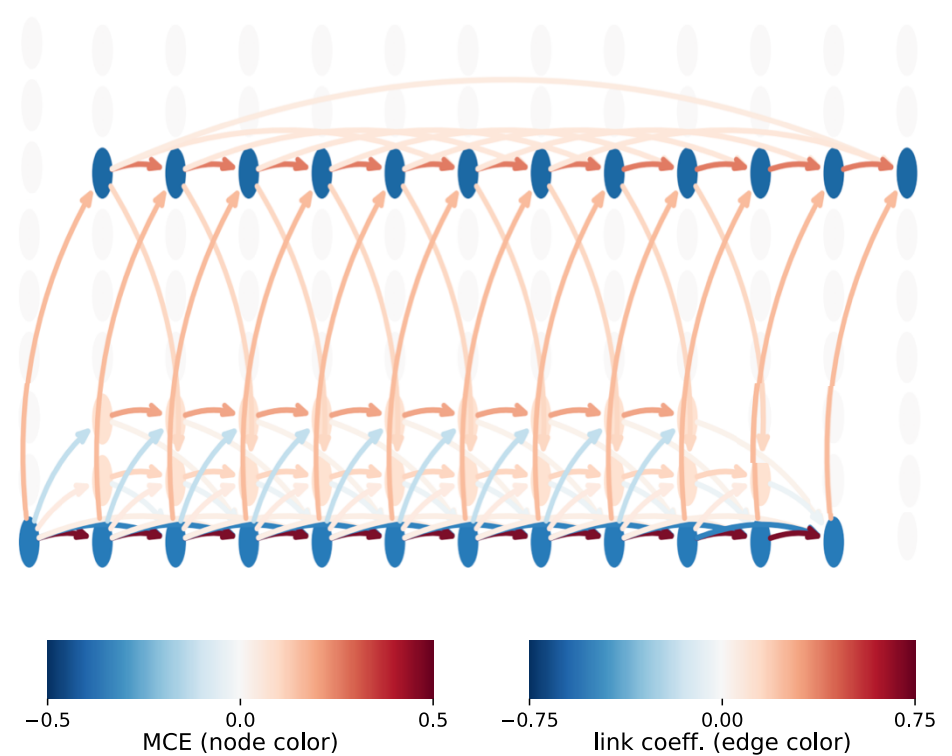

FIG. 7. Causal pathways mediating the response of $850 \mathrm{hPa}$ Arctic temperature $T_{850}(\mathrm{a}, \mathrm{b})$ and inversion strength (c,d) to an imposed $-1 \sigma$ step decrease in sea-ice extent at a lag of twelve weeks, shown as in Figure 6. Panels (a) and (c) show the distribution of mediated causal effects (MCE) separately for the summer-to-fall (JJA $\rightarrow$ SON) and fall-to-winter (SON $\rightarrow$ DJF) transitions. Panels (b) and (d) show the time series graph for CESM ensemble member 3 in the fall-to-winter transition. For simplicity, visualization in panels (b) and (d) is limited to the primary causal pathways $(\operatorname{MCE}(12)> \pm .01)$.

this result by investigating the $\mathrm{CO}_{2}$-forced response of the Arctic lower troposphere over the course of the CESM climate change simulation. This examination provides insight into the vertical extent of the atmospheric response to a step-decrease in sea-ice extent, as well as its relation- ship to the seasonal reductions in boundary-layer stability illustrated in Figure 1a.

First, we investigate how increases in longwave cloud radiative effect could counteract the weakening inversion due to sea-ice loss (Fig. 7c), while, at the same time, fa- 
cilitating seasonally dependent temperature responses at $850 \mathrm{hPa}$ (Fig. 7a). Since increases in the longwave cloud radiative effect imply enhanced downward longwave surface radiation, additional mechanisms must be considered to explain these peculiar mediating effects. Figure 8 shows projected changes in cloud altitude and total water content averaged over the Arctic Ocean. These variables are particularly useful for resolving the ambiguity because they are the primary contributors to positive longwave cloud feedbacks (Zelinka et al. 2012). In CESM-LE, the altitude of maximum Arctic Ocean cloud coverage shifts upward during fall and winter (Fig. 8a). In the same seasons, cloud water content increases throughout the lower and mid-troposphere, with the largest increases in water content $\left(10 \mathrm{~g} \mathrm{~m}^{-2}\right)$ occurring near $850 \mathrm{hPa}$ (Fig. $8 \mathrm{~b}$ ). These connections are supported by re-analysis products and satellite observations in marginal sea-ice zones during Arctic fall, where a deepened atmospheric boundary layer permits upward shifts in both cloud coverage and relative humidity (Schweiger et al. 2008). Cloud changes are also reflected in the changing vertical structure of atmospheric heating rates over the 21 st century, which features increased evaporative cooling near the Arctic surface and increased condensational heating near $850 \mathrm{hPa}$ (Fig. 9a, blue curves). We find that variability in $\mathrm{LW}_{\mathrm{CRE}}$ is strongly correlated with 850 $\mathrm{hPa}$ condensational heating over sea-ice regions, especially in fall $(r>.6)$ and winter $(r>.8$, not shown). This correlation suggests that the near-surface warming impact of sea-ice driven $\mathrm{LW}_{\mathrm{CRE}}$ increases is outweighed by concurrent increases in condensational heating at the cloud deck height (Fig. 8). Indeed, $850 \mathrm{hPa}$ condensational heating experiences larger forced changes than longwave cooling rates (Fig. 9a, brown curves), which are likely associated with Arctic cloud emissivity (Curry et al. 1996; Turner et al. 2018). The RCP8.5 changes thus provide a physically plausible explanation for how an increase in $\mathrm{LW}_{\mathrm{CRE}}$ may be associated with a reduced weakening of the inversion (Fig. $7 \mathrm{c}, \mathrm{d}$ ). We note that cloud properties and heating rates are not included in our causal networks, which prevents them from distinguishing cloud-driven longwave cooling (weakening inversion strength) from cloud-driven condensational heating (increasing inversion strength). However, the vertical profiles in Figure 8 and Figure 9 suggest condensational heating as the dominant mechanism.

Changes in evaporation and condensation are primarily compensated by the vertical diffusion of turbulent heat fluxes (Fig. 9a, green curves), consistent with the mediated causal effects shown in Figure 7. Enhanced vertical diffusion near the Arctic surface corresponds to enhanced upward turbulent heat fluxes (Fig. 2b, Fig. 3i,Fig. 7c,d), accomplishing an upward transfer of heat away from the Arctic surface. Notably, no season features changes in shortwave heating rates (Fig. 9a, orange curves). The constant shortwave atmospheric heating over the 21 st century is consistent with the minimal cloud changes seen in summer and spring (Fig. 8), as well as our causal networks, which show that shortwave processes do not mediate the atmospheric temperature response to enhanced latent heat flux convergence (Fig. 6) or sea-ice loss (Fig. 7).

The sum of these four atmospheric heating rate changes is displayed in Figure 9b. Not surprisingly, seasons with the largest, most vertically extensive increases in net vertical heating rate are the same seasons featuring changes in boundary-layer inversion strength (Fig. 1a). Winter features the largest 21 st century decrease in boundary-layer inversion strength and the largest increase in lower tropospheric net vertical heating rate. Similar, smaller changes are seen in spring and fall. In summer, 21st century Arctic warming is vertically uniform, and Figure $9 \mathrm{~b}$ shows negligible changes in the net heating rate. This relationship implies that when climatological temperature inversions are eroded, especially in winter, near-surface warming anomalies can be mixed upward through a larger depth of the troposphere.

\section{Summary and Discussion}

We use causal effect networks from a fully coupled climate change simulation to quantify the Arctic's temperature sensitivity to $1 \sigma$ perturbations in sea-ice extent and atmospheric heat flux convergence. First, we show that each warming source drives distinct changes in lowertropospheric temperatures during fall and winter. In the weeks following a step-increase in latent heat flux convergence, the Arctic lower troposphere adjusts towards more uniform warming with small net changes in boundary layer inversion strength. By contrast, sea-ice loss in the melt season leads to surface-amplified warming in fall and winter, which weakens the climatological temperature inversion. Boundary-layer stability is maintained during spring and summer, which feature relatively less warming in response to sea-ice loss. Taken together, these causal effects imply that, of our two proposed drivers, local sea-ice loss is more important in setting the magnitude of the highlatitude lapse rate feedback. These results do not define an ultimate primary cause of Arctic-amplified warming, but rather characterize the proximate causes of $T_{850}$ and inversion strength changes. It is ambiguous to define any variable in our causal networks as an independent control on the surface energy budget. For instance, a downward longwave radiation perturbation (associated with $\mathrm{CO}_{2}$ forcing) could cause sea-ice loss and subsequent Arctic surface warming, but downward longwave radiation is itself tightly coupled to surface temperature (Vargas Zeppetello et al. 2019). Despite this challenge, our analyses are nonetheless able to provide a robust description of how various process interactively set the Arctic vertical warming structure. 


\section{a. Cloud Coverage}
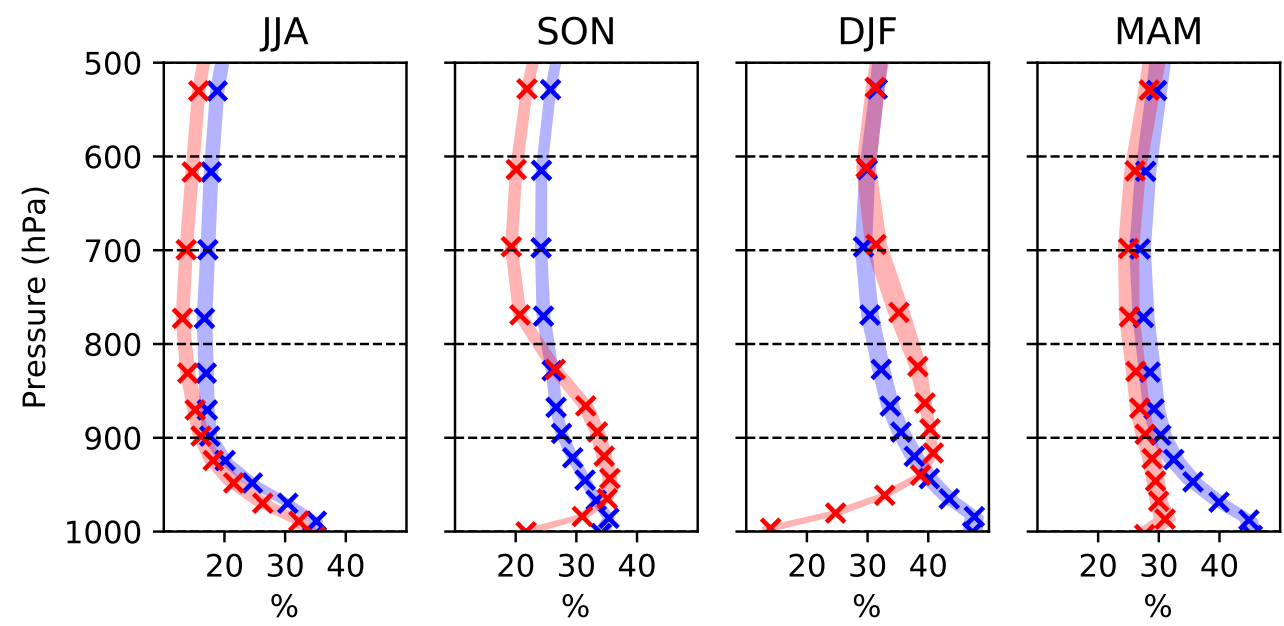

b. Cloud Water Path
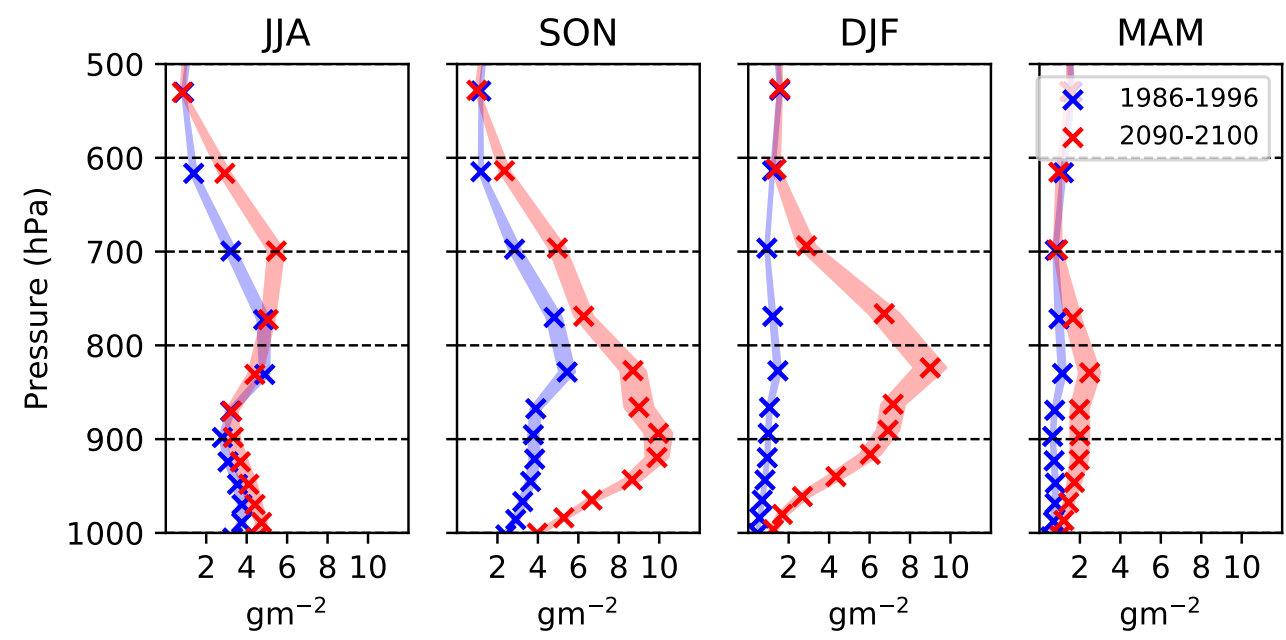

FIG. 8. The 21st century, RCP8.5-forced change in Arctic atmospheric (a) cloud coverage (CLOUD) and (b) in-cloud total water path (liquid+ice, ICLDTWP) in the Community Earth System Model, Large Ensemble (CESM-LE). Vertical profiles show the Arctic-average 1986-1996 (blue) and 2090-2100 (red) climatologies separately for each season, displayed as in Figure 1. For all vertical profiles, the Arctic is defined as the spatial average within the annual mean sea-ice edge (1986-1996 15\% concentration contour).

After quantifying the total causal effect of local and remote perturbations, we examine how the net Arctic warming response is mediated by changes in the surface energy budget. On multi-week timescales, we find that midtropospheric latent heat flux convergence is able to warm the Arctic surface by reducing longwave surface cooling. This indirect warming pathway, characteristic of a local water vapor feedback, is comparable to the more immediate $850 \mathrm{hPa}$ temperature response, leading to only small inversion changes in fall and winter (Fig. 10), consistent with prior observation-based research on Arctic moist intrusions (Woods et al. 2013; Woods and Caballero 2016). The mediating impact of surface changes also demonstrates that moist transport can drive Arctic surface warming without lapse rate changes, even if the causal effect of sea-ice perturbations dominate on longer time scales. A similar role for fast atmospheric processes has been demonstrated in recent CMIP5 experiments, where transport-driven Arctic amplification emerges before sea-ice loss as a rapid response to instantaneous $\mathrm{CO}_{2}$ quadrupling (Previdi et al. 2020). In observations and reanalyses, the fast processes are characterized by synoptic-scale atmospheric variability in Arctic moisture fluxes, which includes Rossby wave breaking and atmospheric blocking (Papritz 2020), atmospheric rivers (Baggett et al. 2016), and cyclone activity (Dufour et al. 2016).

During both fall and winter, we find that the atmospheric response to sea-ice loss is facilitated by an increase in up- 
a. Vertical Heating Rates
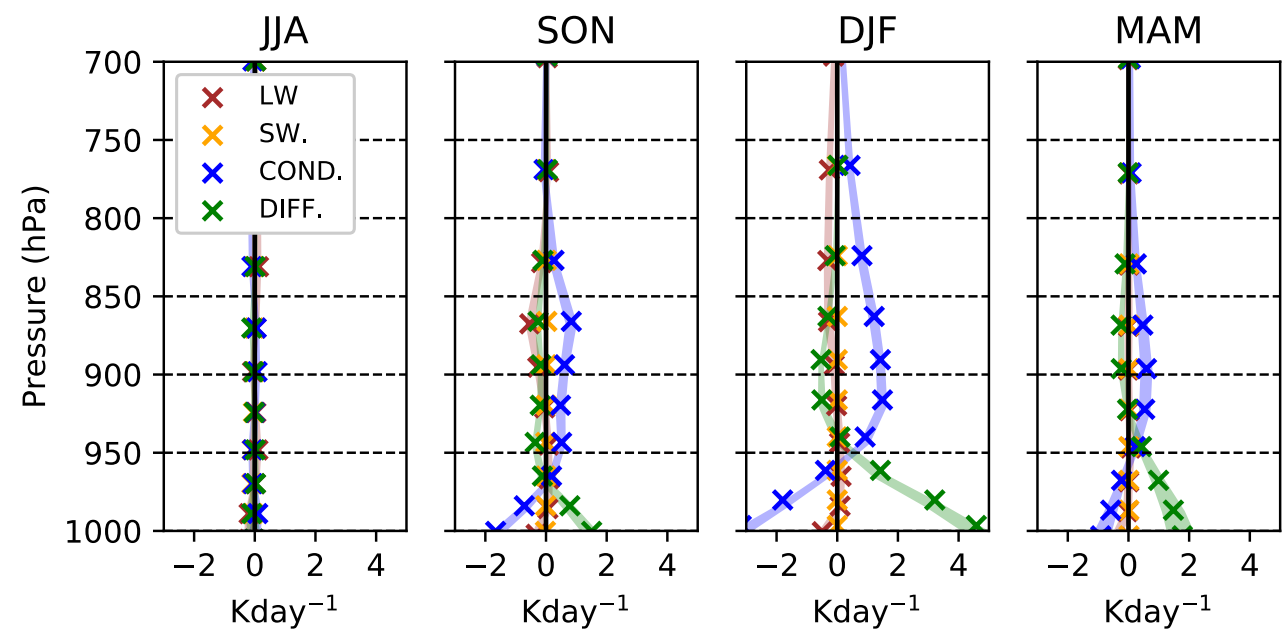

b. Net Change in Vertical Heating Rate
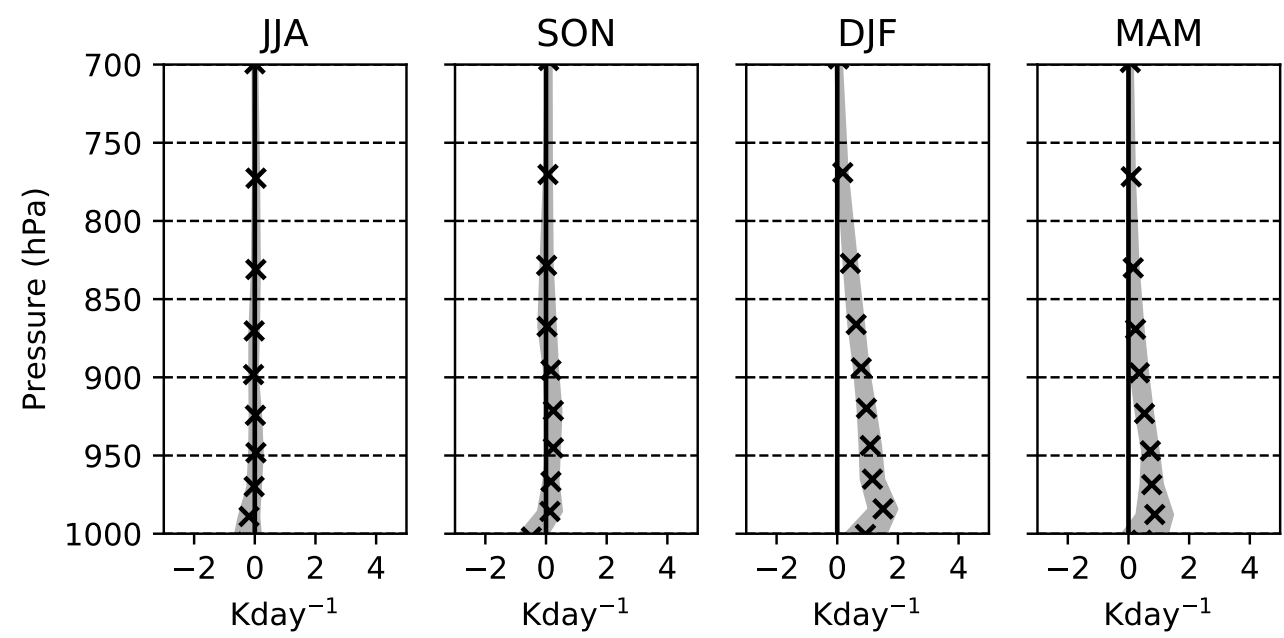

FIG. 9. The 21st century, RCP8.5-forced change in vertical heating rates associated with longwave radiative cooling (LW, brown), shortwave radiative heating ( $\mathrm{SW}$, orange), condensational heating (COND, blue) and the vertical diffusion of turbulent heat fluxes (DIFF, green) in the Community Earth System Model, Large Ensemble (CESM-LE). Changes are calculated as the difference between the 2090-2100 and 1986-1996 climatologies and are shown for individual heating rates (a) and their sum (b, black). The CESM ensemble average and ensemble spread are separated for each season and displayed as in Figure 8.

ward turbulent heat fluxes and cloud-driven condensational heating, with the vertical extent of atmospheric heating maximizing in winter; the large wintertime decreases in inversion strength are consistent with a higher cloud deck and a more extensive vertical diffusion of turbulent heat fluxes. Indeed, both observations and models have demonstrated that the cloud response to sea-ice loss is regime dependent, with lower tropospheric stability controlling the altitude of the cloud deck (Barton et al. 2012). This regime dependence is also evident in the minimal cloud changes in summer, when high static stability is maintained throughout the 21 st century. As noted in prior studies, Arctic cloud coverage and longwave optical depth can increase over newly open water if there is sufficient thermal coupling between the surface and the overlying atmosphere (Kay and Gettelman 2009; Morrison et al. 2019). As boundary-layer inversions erode under anthropogenic forcing, we expect this thermal coupling will increase.

This study only considers the physical representation of clouds in the CESM large ensemble, but cloud parameterization schemes remain bias-prone in the Arctic (Tan and Storelvmo 2019) and vary widely across models, causing substantial differences in climate sensitivity among them (Zelinka et al. 2020). Accordingly, future work is needed to diagnose similar cause-effect relationships across a range of climate models and observations. The atmospheric 
$-\nabla_{500} \cdot L[\overline{v q}](\mathrm{t}-4) \rightarrow$ Inversion Strength (t)

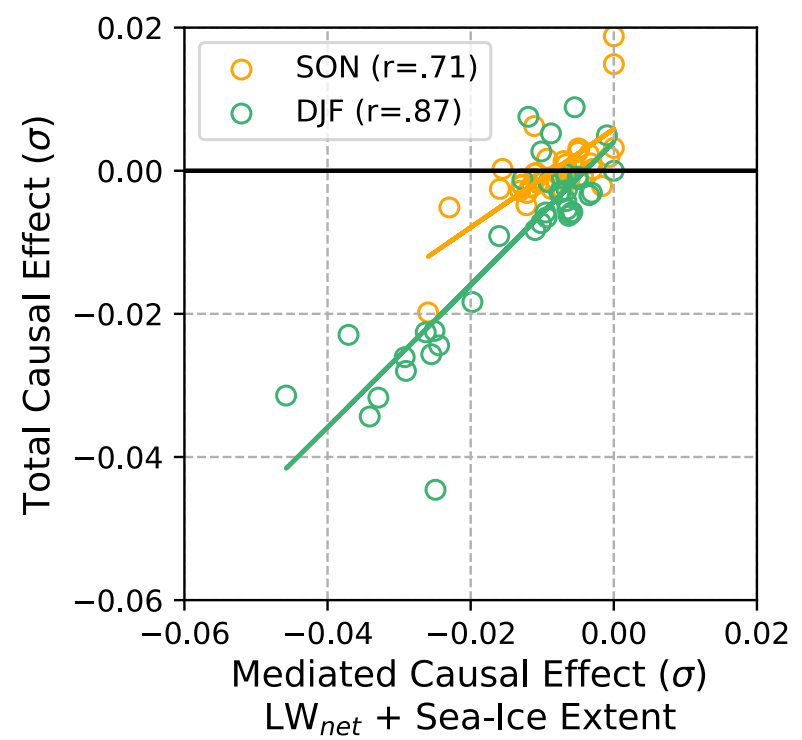

FIg. 10. The causal effect of an imposed $+1 \sigma$ step increase in $500 \mathrm{hPa}$ Arctic latent heat flux convergence $\left(-\nabla_{500} \cdot L[\overline{v q}]\right)$ on Arctic inversion strength at a lag of four weeks (y-axis) and the mediating impact of changes in surface conditions (net surface longwave radiative flux and sea-ice extent, $x$-axis). Negative causal effects indicate a weakening inversion and positive effects indicate a strengthening inversion. Values correspond to the causal effect distributions in Figure $6 \mathrm{c}$ and are shown for individual CESM ensemble members (open circles) in fall (SON) and winter (DJF). The relationship between the two quantities is illustrated with Pearson correlation coefficients (r) and linear lines of best fit for each season.

component of CESM1 (CAM5), for instance, is prone to lacking the cloudy state of the boundary layer in Arctic winter (Pithan et al. 2016). As a consequence, the strength of the DJF climatological temperature inversion at the start of our time series (1986-1996) is likely overestimated due to strong radiative cooling (Fig. 1a). Relatedly, the DJF incloud total water path climatology is likely underestimated (Fig. 8b). The newly released CESM2 has addressed some of these biases, demonstrating increased total cloud liquid, downwelling surface longwave radiation, and surface temperature (McIlhattan et al. 2020).

In conclusion, our causal networks provide evidence that the vertical structure of Arctic warming is strongly tied to sea-ice loss. At first, sea-ice loss leads to a surfaceamplified warming that is characteristic of the positive high-latitude lapse rate feedback. Once warming is large enough to erode the temperature inversion, the Arctic surface becomes more strongly coupled with the atmosphere aloft. Prior feedback studies have suggested that reduced boundary-layer inversion strength will slow the rate of Arctic warming in the future; as climatological stable stratification weakens, the high-latitude lapse rate feedback may become less positive (Bintanja et al. 2011, 2012). More recent research has argued that, because the polar atmosphere is in radiative-advective equilibrium (Cronin and Jansen 2016), lapse rate changes are dependent on the type of perturbation and may be influenced by surface-based processes (Boeke et al. 2020; Feldl et al. 2020), $\mathrm{CO}_{2}$ and water vapor increases (Henry et al. 2021), and poleward atmospheric heat transport (Feldl et al. 2017a; Henry et al. 2021; Hahn et al. 2020). While our results indicate the predominance of local warming sources (i.e., sea ice loss), the atmosphere and cryosphere exhibit different timescales of variability. Future work will seek to integrate the causal effect of step-changes in climate drivers to predict the Arctic temperature response to transient forcings. Causal network analysis offers a flexible methodology for uncovering such relationships in any set of time series, observed or simulated, without the need for targeted modeling experiments. We encourage their continued use for understanding the future evolution of climate change in the 21 st century.

Acknowledgments. Support for Z.S.K. was provided by the National Science Foundation Graduate Research Fellowship Program under Grant No. (NSF DGE-1842400). N.F. was supported by NSF grant AGS-1753034.

Data availability statement. CESM Large Ensemble datasets analyzed during the current study are available on Earth System Grid. (https://www.cesm.ucar.edu/projects/communityprojects/LENS/data-sets.html, Kay et al. 2015).

\section{References}

Alexeev, V., P. L. Langen, and J. R. Bates, 2005: Polar amplification of surface warming on an aquaplanet in "ghost forcing" experiments without sea ice feedbacks. Climate Dynamics, 24 (7-8), 655-666.

Armour, K. C., N. Siler, A. Donohoe, and G. H. Roe, 2019: Meridional atmospheric heat transport constrained by energetics and mediated by large-scale diffusion. Journal of Climate, 32 (12), 3655-3680.

Auclair, G., and L. B. Tremblay, 2018: The role of ocean heat transport in rapid sea ice declines in the community earth system model large ensemble. Journal of Geophysical Research: Oceans, 123 (12), 8941-8957.

Baggett, C., and S. Lee, 2017: An identification of the mechanisms that lead to Arctic warming during planetary-scale and synopticscale wave life cycles. Journal of the Atmospheric Sciences, 74 (6), 1859-1877.

Baggett, C., S. Lee, and S. Feldstein, 2016: An investigation of the presence of atmospheric rivers over the North Pacific during planetaryscale wave life cycles and their role in Arctic warming. Journal of the Atmospheric Sciences, 73 (11), 4329-4347.

Barton, N. P., S. A. Klein, J. S. Boyle, and Y. Y. Zhang, 2012: Arctic synoptic regimes: Comparing domain-wide Arctic cloud observations with CAM4 and CAM5 during similar dynamics. Journal of Geophysical Research: Atmospheres, 117 (D15). 
Bintanja, R., R. Graversen, and W. Hazeleger, 2011: Arctic winter warming amplified by the thermal inversion and consequent low infrared cooling to space. Nature Geoscience, 4 (11), 758-761.

Bintanja, R., and E. Van der Linden, 2013: The changing seasonal climate in the Arctic. Scientific reports, 3 (1), 1-8.

Bintanja, R., E. Van der Linden, and W. Hazeleger, 2012: Boundary layer stability and Arctic climate change: A feedback study using EC-Earth. Climate dynamics, 39 (11), 2659-2673.

Boeke, R. C., and P. C. Taylor, 2018: Seasonal energy exchange in sea ice retreat regions contributes to differences in projected Arctic warming. Nature communications, $\mathbf{9}(\mathbf{1}), 1-14$.

Boeke, R. C., P. C. Taylor, and S. A. Sejas, 2020: On the nature of the Arctic's positive lapse-rate feedback. Geophysical Research Letters, e2020GL091109.

Cardinale, C. J., B. E. Rose, A. L. Lang, and A. Donohoe, 2021: Stratospheric and tropospheric flux contributions to the polar cap energy budgets. Journal of Climate, 34 (11), 4261-4278.

Cronin, T. W., and M. F. Jansen, 2016: Analytic radiative-advective equilibrium as a model for high-latitude climate. Geophysical Research Letters, 43 (1), 449-457.

Curry, J. A., J. L. Schramm, W. B. Rossow, and D. Randall, 1996: Overview of Arctic cloud and radiation characteristics. Journal of Climate, 9 (8), 1731-1764.

Dai, A., D. Luo, M. Song, and J. Liu, 2019: Arctic amplification is caused by sea-ice loss under increasing $\mathrm{CO}_{2}$. Nature communications, $10(\mathbf{1}), 1-13$.

Deser, C., R. Tomas, M. Alexander, and D. Lawrence, 2010: The seasonal atmospheric response to projected Arctic sea ice loss in the late twenty-first century. Journal of Climate, 23 (2), 333-351.

Ding, Q., J. M. Wallace, D. S. Battisti, E. J. Steig, A. J. Gallant, H.-J. Kim, and L. Geng, 2014: Tropical forcing of the recent rapid Arctic warming in northeastern Canada and Greenland. Nature, 509 (7499), 209-212.

Dong, Y., C. Proistosescu, K. C. Armour, and D. S. Battisti, 2019: Attributing historical and future evolution of radiative feedbacks to regional warming patterns using a Green's function approach: The preeminence of the western Pacific. Journal of Climate, 32 (17), $5471-5491$

Dufour, A., O. Zolina, and S. K. Gulev, 2016: Atmospheric moisture transport to the arctic: Assessment of reanalyses and analysis of transport components. Journal of Climate, 29 (14), 5061-5081.

England, M. R., I. Eisenman, N. J. Lutsko, and T. J. Wagner, 2021: The recent emergence of Arctic Amplification. Geophysical Research Letters, 48 (15), e2021GL094 086.

Feldl, N., B. T. Anderson, and S. Bordoni, 2017a: Atmospheric eddies mediate lapse rate feedback and Arctic amplification. Journal of Climate, 30 (22), 9213-9224.

Feldl, N., S. Bordoni, and T. M. Merlis, 2017b: Coupled high-latitude climate feedbacks and their impact on atmospheric heat transport. Journal of Climate, 30 (1), 189-201.

Feldl, N., S. Po-Chedley, H. K. Singh, S. Hay, and P. J. Kushner, 2020: Sea ice and atmospheric circulation shape the high-latitude lapse rate feedback. npj Climate and Atmospheric Science, 3 (1), 1-9.
Gong, T., S. Feldstein, and S. Lee, 2017: The role of downward infrared radiation in the recent Arctic winter warming trend. Journal of Climate, 30 (13), 4937-4949.

Graversen, R. G., and M. Burtu, 2016: Arctic amplification enhanced by latent energy transport of atmospheric planetary waves. Quarterly Journal of the Royal Meteorological Society, 142 (698), 2046-2054.

Graversen, R. G., and P. L. Langen, 2019: On the role of the atmospheric energy transport in $2 \times \mathrm{CO}_{2}$-induced polar amplification in CESM1. Journal of Climate, 32 (13), 3941-3956.

Graversen, R. G., P. L. Langen, and T. Mauritsen, 2014: Polar amplification in CCSM4: Contributions from the lapse rate and surface albedo feedbacks. Journal of Climate, 27 (12), 4433-4450.

Graversen, R. G., and M. Wang, 2009: Polar amplification in a coupled climate model with locked albedo. Climate Dynamics, 33 (5), 629_ 643.

Hahn, L., K. C. Armour, D. S. Battisti, A. Donohoe, A. Pauling, and C. Bitz, 2020: Antarctic elevation drives hemispheric asymmetry in polar lapse rate climatology and feedback. Geophysical Research Letters, 47 (16), e2020GL088 965.

Held, I. M., and B. J. Soden, 2006: Robust responses of the hydrological cycle to global warming. Journal of climate, 19 (21), 5686-5699.

Henry, M., T. M. Merlis, N. J. Lutsko, and B. E. Rose, 2021: Decomposing the drivers of polar amplification with a single-column model. Journal of Climate, 34 (6), 2355-2365.

Holland, M. M., and C. M. Bitz, 2003: Polar amplification of climate change in coupled models. Climate Dynamics, 21 (3-4), 221-232.

Hwang, Y.-T., D. M. Frierson, and J. E. Kay, 2011: Coupling between Arctic feedbacks and changes in poleward energy transport. Geophysical Research Letters, 38 (17).

Kay, J. E., and A. Gettelman, 2009: Cloud influence on and response to seasonal Arctic sea ice loss. Journal of Geophysical Research: Atmospheres, 114 (D18).

Kay, J. E., and Coauthors, 2015: The Community Earth System Model (CESM) Large Ensemble project: a community resource for studying climate change in the presence of internal climate variability. Bulletin of the American Meteorological Society, 96 (8), 1333-1349.

Kim, D., S. M. Kang, Y. Shin, and N. Feldl, 2018: Sensitivity of polar amplification to varying insolation conditions. Journal of Climate, 31 (12), 4933-4947.

Kostov, Y., J. Marshall, U. Hausmann, K. C. Armour, D. Ferreira, and M. M. Holland, 2017: Fast and slow responses of Southern Ocean sea surface temperature to SAM in coupled climate models. Climate Dynamics, 48 (5-6), 1595-1609.

Kretschmer, M., D. Coumou, J. F. Donges, and J. Runge, 2016: Using causal effect networks to analyze different Arctic drivers of midlatitude winter circulation. Journal of Climate, 29 (11), 4069-4081.

Lee, S., 2012: Testing of the tropically excited Arctic warming mechanism (TEAM) with traditional El Niño and La Niña. Journal of Climate, 25 (12), 4015-4022.

Lee, S., T. Gong, S. B. Feldstein, J. A. Screen, and I. Simmonds, 2017: Revisiting the cause of the 1989-2009 Arctic surface warming using the surface energy budget: Downward infrared radiation dominates the surface fluxes. Geophysical Research Letters, 44 (20), 10-654. 
Liu, C., and E. A. Barnes, 2015: Extreme moisture transport into the Arctic linked to Rossby wave breaking. Journal of Geophysical Research: Atmospheres, 120 (9), 3774-3788.

Lu, J., and M. Cai, 2009: Seasonality of polar surface warming amplification in climate simulations. Geophysical Research Letters, 36 (16).

Manabe, S., and R. J. Stouffer, 1980: Sensitivity of a global climate model to an increase of $\mathrm{CO}_{2}$ concentration in the atmosphere. Journal of Geophysical Research: Oceans, 85 (C10), 5529-5554.

Manabe, S., and R. T. Wetherald, 1975: The effects of doubling the $\mathrm{CO}_{2}$ concentration on the climate of a general circulation model. Journal of the Atmospheric Sciences, 32 (1), 3-15.

McGraw, M. C., C. F. Baggett, C. Liu, and B. D. Mundhenk, 2020: Changes in Arctic moisture transport over the North Pacific associated with sea ice loss. Climate Dynamics, 54 (1), 491-506.

McIlhattan, E. A., J. E. Kay, and T. S. L'Ecuyer, 2020: Arctic clouds and precipitation in the Community Earth system Model Version 2. Journal of Geophysical Research: Atmospheres, 125 (22), e2020JD032 521.

Merlis, T. M., and M. Henry, 2018: Simple estimates of polar amplification in moist diffusive energy balance models. Journal of Climate, 31 (15), 5811-5824.

Morrison, A., J. Kay, W. Frey, H. Chepfer, and R. Guzman, 2019: Cloud response to Arctic sea ice loss and implications for future feedback in the CESM1 climate model. Journal of Geophysical Research: Atmospheres, 124 (2), 1003-1020.

Papritz, L., 2020: Arctic lower-tropospheric warm and cold extremes: Horizontal and vertical transport, diabatic processes, and linkage to synoptic circulation features. Journal of Climate, 33 (3), 993-1016.

Park, D.-S. R., S. Lee, and S. B. Feldstein, 2015a: Attribution of the recent winter sea ice decline over the Atlantic sector of the Arctic ocean. Journal of climate, 28 (10), 4027-4033.

Park, H.-S., S. Lee, S.-W. Son, S. B. Feldstein, and Y. Kosaka, 2015b: The impact of poleward moisture and sensible heat flux on Arctic winter sea ice variability. Journal of Climate, 28 (13), 5030-5040.

Pearl, J., 2013: Linear models: a useful microscope for causal analysis. Journal of Causal Inference, 1 (1), 155-170.

Pearl, J., and Coauthors, 2000: Models, reasoning and inference. Cambridge, UK: Cambridge University Press.

Pithan, F., and T. Mauritsen, 2014: Arctic amplification dominated by temperature feedbacks in contemporary climate models. Nature Geoscience, 7 (3), 181-184.

Pithan, F., and Coauthors, 2016: Select strengths and biases of models in representing the Arctic winter boundary layer over sea ice: the Larcform 1 single column model intercomparison. Journal of advances in modeling earth systems, 8 (3), 1345-1357.

Previdi, M., T. P. Janoski, G. Chiodo, K. L. Smith, and L. M. Polvani, 2020: Arctic amplification: A rapid response to radiative forcing. Geophysical Research Letters, 47 (17), e2020GL089 933.

Runge, J., and Coauthors, 2015: Identifying causal gateways and mediators in complex spatio-temporal systems. Nature communications, $\mathbf{6}(\mathbf{1}), 1-10$

Runge, J., and Coauthors, 2019: Inferring causation from time series in Earth system sciences. Nature communications, 10 (1), 1-13.
Schweiger, A. J., R. W. Lindsay, S. Vavrus, and J. A. Francis, 2008: Relationships between Arctic sea ice and clouds during autumn. Journal of Climate, 21 (18), 4799-4810.

Screen, J. A., and Coauthors, 2018: Consistency and discrepancy in the atmospheric response to Arctic sea-ice loss across climate models. Nature Geoscience, 11 (3), 155-163.

Serreze, M., A. Barrett, J. Stroeve, D. Kindig, and M. Holland, 2009: The emergence of surface-based Arctic amplification. The Cryosphere, 3 (1), 11.

Serreze, M. C., A. P. Barrett, A. G. Slater, M. Steele, J. Zhang, and K. E. Trenberth, 2007a: The large-scale energy budget of the arctic. Journal of Geophysical Research: Atmospheres, 112 (D11).

Serreze, M. C., M. M. Holland, and J. Stroeve, 2007b: Perspectives on the Arctic's shrinking sea-ice cover. science, 315 (5818), 1533-1536.

Singh, H. K., C. M. Bitz, A. Donohoe, and P. J. Rasch, 2017: A sourcereceptor perspective on the polar hydrologic cycle: Sources, seasonality, and Arctic-Antarctic parity in the hydrologic cycle response to $\mathrm{CO}_{2}$ doubling. Journal of Climate, 30 (24), 9999-10 017

Smith, D. M., and Coauthors, 2019: The Polar Amplification Model Intercomparison Project (PAMIP) contribution to CMIP6: Investigating the causes and consequences of polar amplification. Geoscientific Model Development, 12 (3), 1139-1164.

Spirtes, P., C. N. Glymour, R. Scheines, and D. Heckerman, 2000: Causation, Prediction, and Search. MIT press.

Stramler, K., A. D. Del Genio, and W. B. Rossow, 2011: Synoptically driven Arctic winter states. Journal of Climate, 24 (6), 1747-1762.

Stuecker, M. F., and Coauthors, 2018: Polar amplification dominated by local forcing and feedbacks. Nature Climate Change, 8 (12), 10761081 .

Tan, I., and T. Storelvmo, 2019: Evidence of strong contributions from mixed-phase clouds to Arctic climate change. Geophysical Research Letters, 46 (5), 2894-2902.

Tomas, R. A., C. Deser, and L. Sun, 2016: The role of ocean heat transport in the global climate response to projected Arctic sea ice loss. Journal of Climate, 29 (19), 6841-6859.

Turner, D., M. Shupe, and A. Zwink, 2018: Characteristic atmospheric radiative heating rate profiles in Arctic clouds as observed at Barrow, Alaska. Journal of Applied Meteorology and Climatology, 57 (4), 953-968.

Vargas Zeppetello, L., A. Donohoe, and D. Battisti, 2019: Does surface temperature respond to or determine downwelling longwave radiation? Geophysical Research Letters, 46 (5), 2781-2789.

Winton, M., 2006: Amplified Arctic climate change: What does surface albedo feedback have to do with it? Geophysical Research Letters, 33 (3).

Woods, C., and R. Caballero, 2016: The role of moist intrusions in winter Arctic warming and sea ice decline. Journal of Climate, 29 (12), $4473-4485$

Woods, C., R. Caballero, and G. Svensson, 2013: Large-scale circulation associated with moisture intrusions into the Arctic during winter. Geophysical Research Letters, 40 (17), 4717-4721. 
Yoshimori, M., A. Abe-Ouchi, and A. Laîné, 2017: The role of atmospheric heat transport and regional feedbacks in the Arctic warming at equilibrium. Climate Dynamics, 49 (9-10), 3457-3472.

Zelinka, M. D., S. A. Klein, and D. L. Hartmann, 2012: Computing and partitioning cloud feedbacks using cloud property histograms. Part II: Attribution to changes in cloud amount, altitude, and optical depth. Journal of Climate, 25 (11), 3736-3754.

Zelinka, M. D., T. A. Myers, D. T. McCoy, S. Po-Chedley, P. M. Caldwell, P. Ceppi, S. A. Klein, and K. E. Taylor, 2020: Causes of higher climate sensitivity in CMIP6 models. Geophysical Research Letters, 47 (1), e2019GL085 782. 


\title{
Supporting Information for "Causes of the Arctic's Lower-Tropospheric Warming Structure"
}

\author{
Zachary S. Kaufman and Nicole Feldl
}

\author{
University of California, Santa Cruz, Santa Cruz, California
}

Contents of this file

1. Figure S1

2. Figure $\mathrm{S} 2$

3. Figure S3

4. Figure S4 


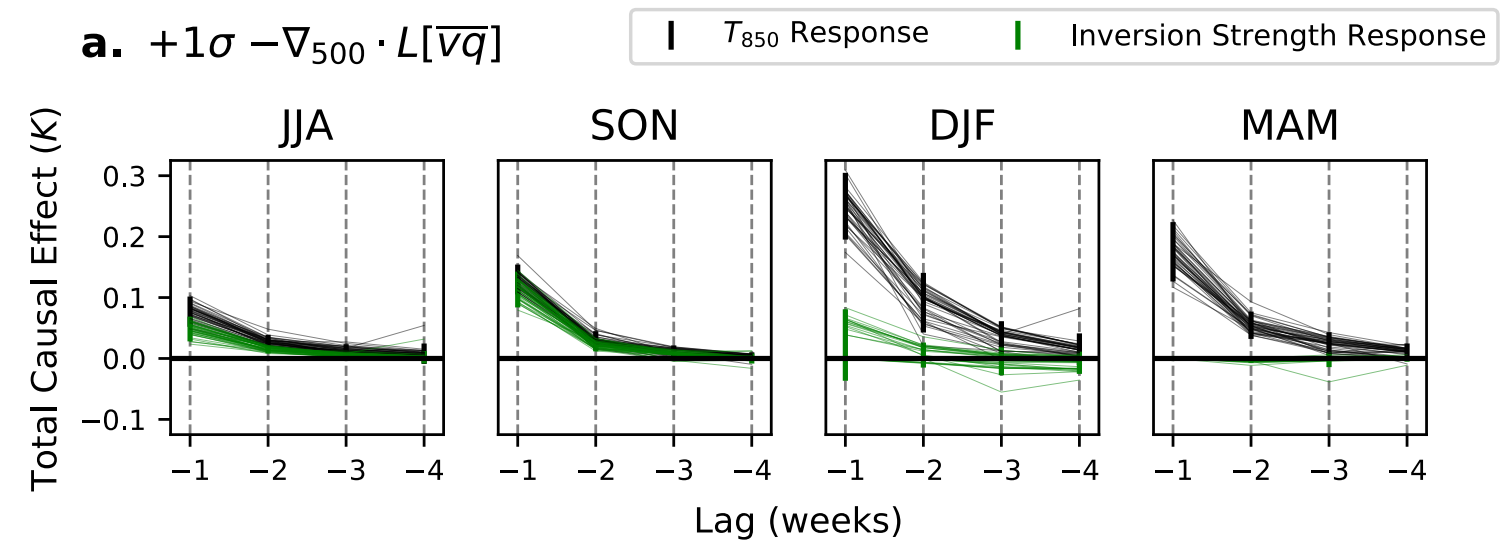

$$
\text { b. }-1 \sigma-\nabla_{500} \cdot c_{p}[\overline{V T}]
$$
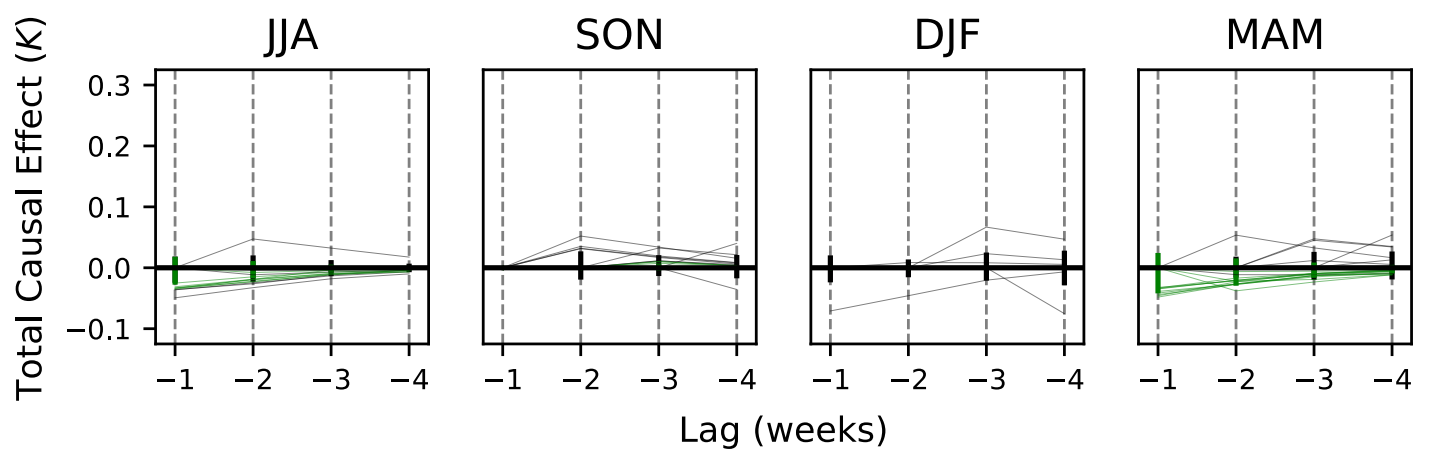

Figure S1: The predicted change in Arctic atmospheric temperature caused by (a) an imposed $+1 \sigma$ step increase in $500 \mathrm{hPa}$ Arctic latent heat flux convergence $\left(-\nabla_{500} \cdot L[\overline{v q}]\right)$, (b) a $-1 \sigma$ step decrease in $500 \mathrm{hPa}$ sensible heat flux convergence $\left(-\nabla_{500} \cdot c_{p}[\overline{v T}]\right)$, shown as in Figure 5a,b. In this figure, sensible heat flux convergence is evaluated at $500 \mathrm{hPa}$ instead of $850 \mathrm{hPa}$. 


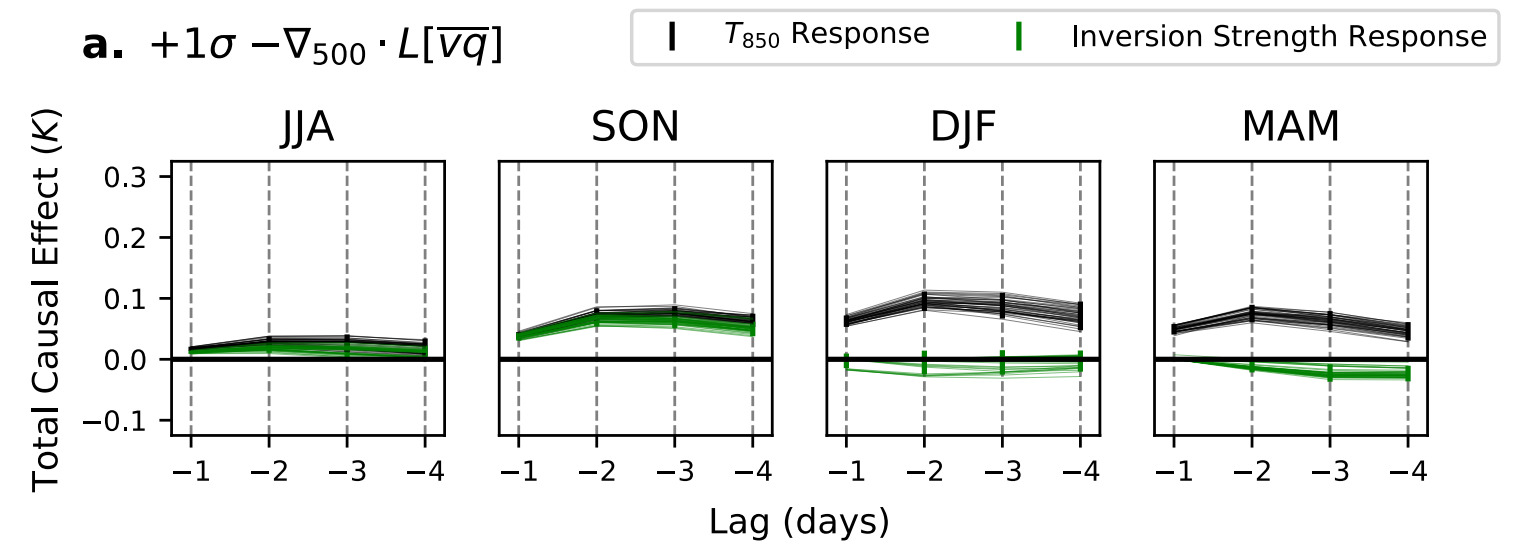

$$
\text { b. }-1 \sigma-\nabla_{850} \cdot c_{p}[\overline{v T}]
$$
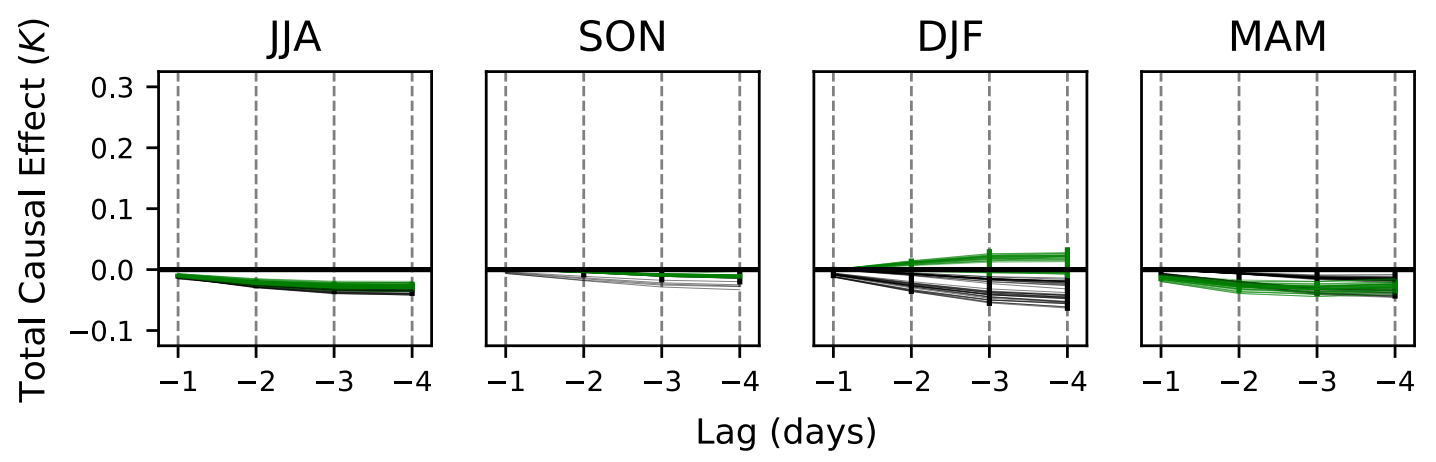

Figure S2: The predicted change in Arctic atmospheric temperature caused by (a) an imposed $+1 \sigma$ step increase in $500 \mathrm{hPa}$ Arctic latent heat flux convergence $\left(-\nabla_{500} \cdot L[\overline{v q}]\right)$, (b) a $-1 \sigma$ step decrease in $500 \mathrm{hPa}$ sensible heat flux convergence $\left(-\nabla_{850} \cdot c_{p}[\overline{v T}]\right)$, shown as in Figure $5 \mathrm{a}$, b. In this figure, causal networks are evaluated at higher time resolution (daily timesteps). 

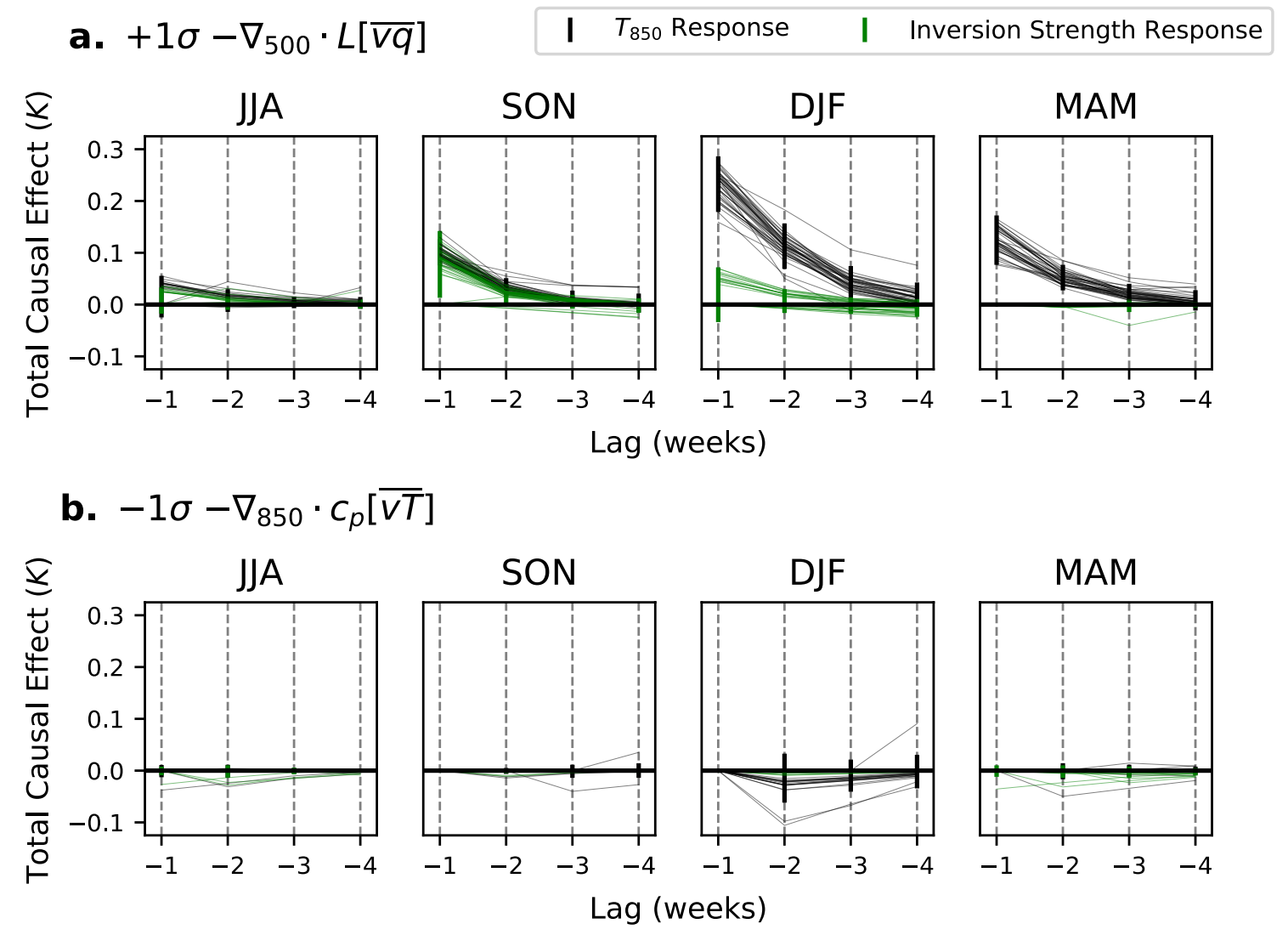

Figure S3: The predicted change in Arctic atmospheric temperature caused by (a) an imposed $+1 \sigma$ step increase in $500 \mathrm{hPa}$ Arctic latent heat flux convergence $\left(-\nabla_{500} \cdot L[\overline{v q}]\right)$, (b) a $-1 \sigma$ step decrease in 850 $\mathrm{hPa}$ sensible heat flux convergence $\left(-\nabla_{850} \cdot c_{p}[\overline{v T}]\right)$, shown as in Figure $5 \mathrm{a}$, b. In this figure, the horizontal averaging domain for causal network input is extended from $70^{\circ}-90^{\circ} \mathrm{N}$ to $60^{\circ}-90^{\circ} \mathrm{N}$. 
Full Spatial Domain

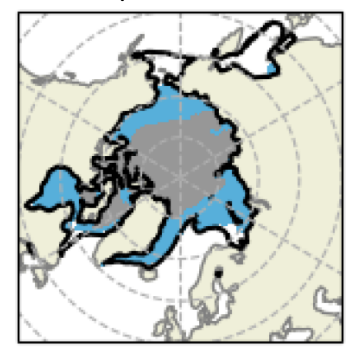

JJA Ice-Covered Regime

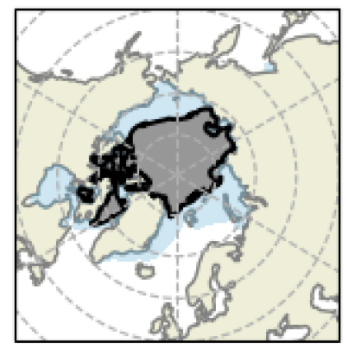

JJA Ice-Retreat Regime

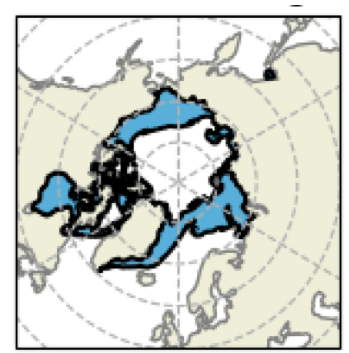

a. $-1 \sigma$ Sea-Ice Extent
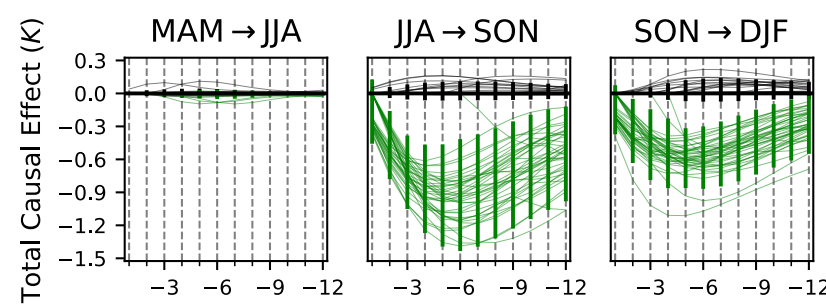

Lag (weeks) b. $-1 \sigma$ Sea-Ice Extent
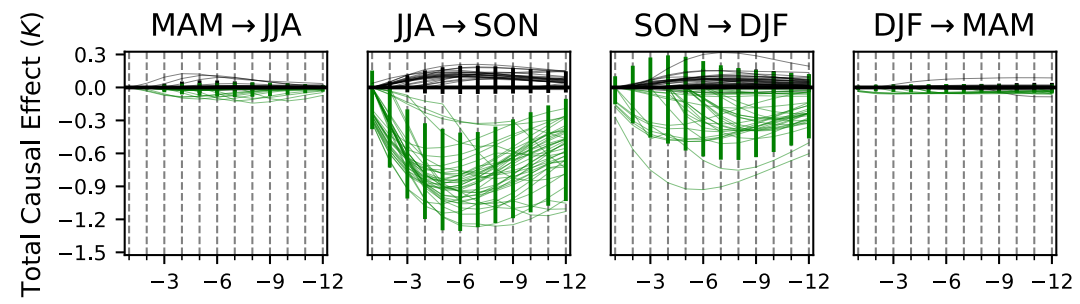

Lag (weeks)

\section{c. $-1 \sigma$ Sea-Ice Extent}
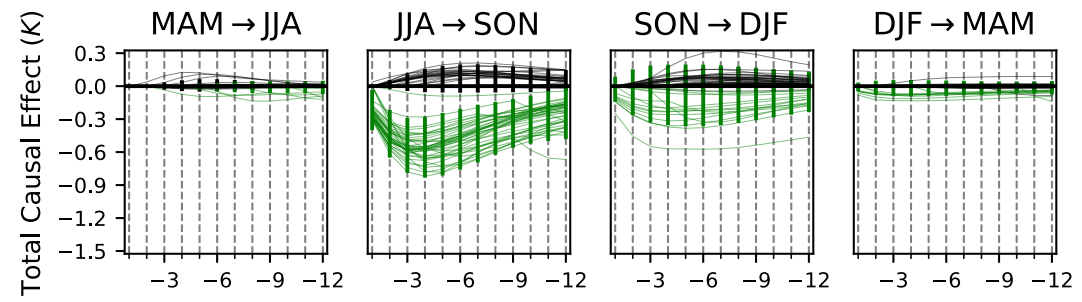

Figure S4: The predicted change in Arctic atmospheric temperature caused by a $-1 \sigma$ step decrease in sea-ice extent, shown as in Figure 5c. In accompanying maps, black lines define the horizontal averaging domain of causal network input in each row. The full spatial domain (a) represents the annual mean, ensemble mean sea-ice edge at the start of the study period (1986-1996). Ice-covered regions (b, gray color) are defined as grid boxes with summer (JJA) sea-ice concentrations $>15 \%$ in the 1986-1996 and 2090-2100 averages. Ice-retreat regions (c, blue color) are identified as grid boxes beginning the simulation with concentrations $>15 \%$ for 1986-1996 and dropping to concentrations < 15\% for 2090-2100. 